Article

\title{
Enhanced Oil Recovery by a Suspension of Core-Shell Polymeric Nanoparticles in Heterogeneous Low-Permeability Oil Reservoirs
}

\author{
Yunqian Long ${ }^{1,2, *} \mathbb{C}$, Renyi Wang ${ }^{3, *}$, Baikang Zhu ${ }^{2,3}$, Xiaohe Huang ${ }^{3}$, Zhe Leng ${ }^{1}$, Liqiao Chen ${ }^{1}$ \\ and Fuquan Song ${ }^{3}$ \\ 1 Institute of Innovation \& Application, Zhejiang Ocean University, Zhoushan 316022, China; \\ lengzhe12345a@163.com (Z.L.); chenlq118@126.com (L.C.) \\ 2 United National-Local Engineering Laboratory of Harbor Oil \& Gas Storage and Transportation Technology, \\ Zhejiang Ocean University, Zhoushan 316022, China; zszbk@126.com \\ 3 School of Petrochemical \& Energy Engineering, Zhejiang Ocean University, Zhoushan 316022, China; \\ huangxh@zjou.edu.cn (X.H.); songfuquan@zjou.edu.cn (F.S.) \\ * Correspondence: longyunqian@163.com (Y.L.); wry2898@163.com (R.W.); \\ Tel.: +86-580-2262589 (Y.L.); +86-580-2551586 (R.W.)
}

Received: 22 March 2019; Accepted: 10 April 2019; Published: 11 April 2019

\begin{abstract}
Polymeric nanoparticle suspension is a newly developed oil-displacing agent for enhanced oil recovery (EOR) in low-permeability reservoirs. In this work, $\mathrm{SiO}_{2} / \mathrm{P}(\mathrm{MBAAm}-\mathrm{co}-\mathrm{AM})$ polymeric nanoparticles were successfully synthesized by a simple distillation-precipitation polymerization method. Due to the introduction of polymer, the $\mathrm{SiO}_{2} / \mathrm{P}(\mathrm{MBAAm}-\mathrm{co}-\mathrm{AM})$ nanoparticles show a favorable swelling performance in aqueous solution, and their particle sizes increase from 631 to $1258 \mathrm{~nm}$ as the swelling times increase from 24 to $120 \mathrm{~h}$. The apparent viscosity of $\mathrm{SiO}_{2} / \mathrm{P}(\mathrm{MBAAm}-\mathrm{co}-\mathrm{AM})$ suspension increases with an increase of mass concentration and swelling time, whereas it decreases as the salinity and temperature increase. The $\mathrm{SiO}_{2} / \mathrm{P}(\mathrm{MBAAm}-c o-\mathrm{AM})$ suspension behaves like a non-Newtonian fluid at lower shear rates, yet like a Newtonian fluid at shear rates greater than $300 \mathrm{~s}^{-1}$. The EOR tests of the $\mathrm{SiO}_{2} / \mathrm{P}(\mathrm{MBAAm}-\mathrm{co}-\mathrm{AM})$ suspension in heterogeneous, low-permeability cores show that $\mathrm{SiO}_{2} / \mathrm{P}(\mathrm{MBAAm}-\mathrm{co}-\mathrm{AM})$ nanoparticles can effectively improve the sweep efficiency and recover more residual oils. A high permeability ratio can result in a high incremental oil recovery in parallel cores. With an increase of the permeability ratio of parallel cores from 1.40 to 15.49 , the ratios of incremental oil recoveries (low permeability/high permeability) change from 7.69/4.61 to 23.61/8.46. This work demonstrates that this $\mathrm{SiO}_{2} / \mathrm{P}(\mathrm{MBAAm}-c o-\mathrm{AM})$ suspension is an excellent conformance control agent for EOR in heterogeneous, low-permeability reservoirs. The findings of this study can help to further the understanding of the mechanisms of EOR using $\mathrm{SiO}_{2} / \mathrm{P}(\mathrm{MBAAm}-\mathrm{co}-\mathrm{AM})$ suspension in heterogeneous, low-permeability reservoirs.
\end{abstract}

Keywords: core-shell polymeric nanoparticles; enhanced oil recovery; suspension; heterogeneous reservoir; permeability ratio

\section{Introduction}

In recent years, due to the severe heterogeneity of reservoir formations, serious water channeling has become a well-recognized problem in the development of low-permeability reservoirs, as the reservoirs enter into the middle or late stages of waterflooding development [1-4]. When a water flood is carried out in a heterogeneous reservoir, the injected water mainly flows into the high-permeability zones in the formation, leaving most of the low-permeability zones un-swept. This is the so-called conformance problem that is common in heterogeneous reservoirs [5-8]. Water channeling can lead to 
high water production, low oil recovery, rapid reaching of the economic limit, and high residual oil saturation in the low-permeability zones of the reservoir formations. Hence, water control is one of the most important goals for the further development of heterogeneous reservoirs [9-12]. In addition, after many oilfields have experienced water flood for a long period of time, the long-term erosion of the high-permeability zones, caused by water injection, can result in the increased heterogeneity of the reservoirs [13-16]. As a result, the injected water pours more easily into the producing wells along the high-permeability areas, which makes it more difficult to achieve good water control in the reservoir formations. Therefore, it is crucial to plug the high-permeability zones for the sake of recovering more residual oils from un-swept zones for EOR in heterogeneous reservoirs.

Many technologies have been used to control conformance for improving reservoir heterogeneity, reducing the fluidity of displacement fluid, enlarging the swept volume of displacing fluid, and improving oil recovery in heterogeneous reservoirs. Currently, conformance control technologies have been applied in oilfields, including gel treatment [17], polymer flooding [18-20], surfactant-polymer (SP) flooding [21], alkaline-surfactant-polymer (ASP) flooding [22,23], foam flooding [24], and emulsion flooding [25]. Compared with these technologies, it looks promising to use a polymeric nanoparticle suspension as a selective water-shutoff-plugging agent for conformance control treatments in heterogeneous reservoirs. Injecting a large volume of polymeric nanoparticle suspension to plug high-permeability zones and improve oil recovery has become an attractive technology in recent years [26-30]. Polymeric nanoparticle suspension is a system in which polymeric nanoparticles are dispersed in aqueous solution. Polymeric nanoparticles are synthesized by the induction of polymer on the surface of nanoparticles to form a more stable and highly efficient injectant, with a core of nanoparticles and a shell of polymer. There are unparalleled advantages in using polymeric nanoparticle suspension as a conformance control agent [31-35].

A number of polymeric nanoparticle suspensions have been prepared to improve oil recovery in heterogeneous reservoirs in recent years [36-39]. Lai et al. synthesized modified nano-SiO $2 / \mathrm{AA} / \mathrm{AM}$ copolymer (HPMNS) oil displacement agents by free-radical polymerization and carried out indoor displacement tests, and the results indicated that the copolymers can increase both the resistance factor and residual resistance factor in a medium-porous medium under a similar permeability, and they have a stronger mobility control capacity that can effectively improve the EOR [40]. Hu et al. formulated novel, aqueous, partially hydrolyzed, polyacrylamide-based $\mathrm{SiO}_{2}$ nanocomposites and found that the inclusion of silica nanoparticles significantly improves the viscosity and viscoelastic properties of partially hydrolyzed polyacrylamide especially under high temperatures and high salinities [41]. Ju et al. used two types of polysilicon nanoparticles in oil fields to improve oil recovery and enhance water injection and confirmed that polysilicon nanoparticles are effective agents for enhancing water injection capability or improving oil recovery [42]. Liu et al. fabricated a novel, star-like, hydrophobically associative polyacrylamide (SHPAM) used in EOR processes in harsh reservoir conditions, and core flooding tests revealed that SHPAM at a concentration of $1500 \mathrm{mg} / \mathrm{L}$ increases the oil recovery factor by $20 \%$ in sandstone cores [43].

It can be seen from the above references that these polymeric nanoparticle suspensions used in high-permeability reservoirs rely on high viscosity to improve the mobility ratio of fluids, which can realize conformance control to improve the EOR. However, they cannot be injected into or move through a porous medium in low-permeability reservoirs. The new direction in polymeric nanoparticle suspension is to develop a suspension of low viscosity, which mainly depends on plugging at pores to realize conformance control. Therefore, the application of polymeric nanoparticle suspensions can be expanded to low-permeability reservoirs. Compared with the polymeric nanoparticle suspensions reported in the literature, the polymeric nanoparticle suspension used in this study has a low bulk viscosity, similar to water, which can assure a good injectivity in low-permeability reservoirs. Simultaneously, the polymeric nanoparticles can swell from their original nano size to micron size in aqueous solution. As the swollen polymeric nanoparticles are injected into the formation, they can plug large pores to reduce the permeability of high-permeability zones, change the flow direction of 
water, and promote the sweep efficiency of injected water. Moreover, the polymeric nanoparticles can pass through small pores by elastic deformation to achieve deeper seepage in the formation, and they can more effectively reduce the formation permeability away from the water injection well.

In this present research, we tried to synthesize $\mathrm{SiO}_{2} / \mathrm{P}(\mathrm{MBAAm}-\mathrm{co}-\mathrm{AM})$ polymeric nanoparticles using a distillation-precipitation polymerization method. The morphology and microstructure of the obtained polymeric nanoparticles were studied via scanning electron microscopy (SEM), transmission electron microscopy (TEM), Fourier-transform infrared spectroscopy (FT-IR), and thermogravimetric analysis (TGA). We investigated the swelling performances of $\mathrm{SiO}_{2} / \mathrm{P}(\mathrm{MBAAm}-\mathrm{co}-\mathrm{AM})$ nanoparticles in aqueous solution using dynamic light scattering (DLS) and the rheological behavior of $\mathrm{SiO}_{2} / \mathrm{P}(\mathrm{MBAAm}-\mathrm{co}-\mathrm{AM})$ suspension using a viscometer. Finally, we investigated the efficiency of $\mathrm{SiO}_{2} / \mathrm{P}(\mathrm{MBAAm}-\mathrm{co}-\mathrm{AM})$ suspension in improving oil recovery in heterogeneous low-permeability reservoirs via parallel cores flooding tests. The general sketch of this present research is shown in Figure 1.

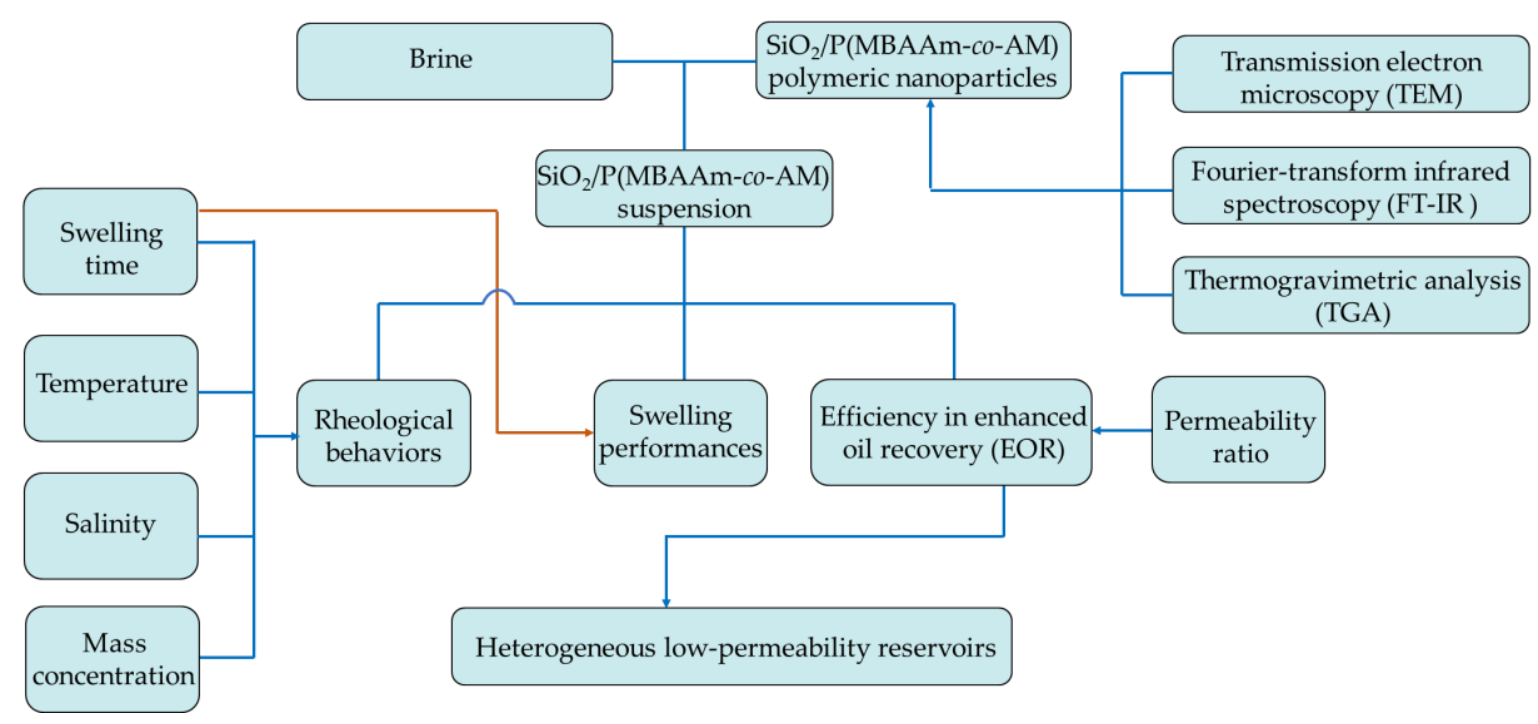

Figure 1. General sketch of this present research.

This article is organized as follows. First, materials and methods are presented. Later, the characterizations of $\mathrm{SiO}_{2}$ and $\mathrm{SiO}_{2} / \mathrm{P}(\mathrm{MBAAm}-c o-\mathrm{AM})$ nanoparticles are analyzed. Then, the swelling performances of $\mathrm{SiO}_{2} / \mathrm{P}(\mathrm{MBAAm}-\mathrm{co}-\mathrm{AM})$ nanoparticles in an aqueous solution as well as the rheological behaviors and the efficiency of $\mathrm{SiO}_{2} / \mathrm{P}(\mathrm{MBAAm}-\mathrm{co}-\mathrm{AM})$ suspension in EOR are discussed. Finally, the summary and conclusions are presented.

\section{Materials and Methods}

\subsection{Materials}

Tetraethyl orthosilicate (TEOS, 28.5\%, Modern Oriental Fine Chemicals Co., Ltd., Beijing, China), acrylamide (AM, Sinopharm Chemical Reagent Co., Ltd., Beijing, China), N, N-methylenebis-acrylamide (MBAA, Sinopharm Chemical Reagent Co., Ltd., Beijing, China), azodiisobutyronitrile (AIBN, Sinopharm Chemical Reagent Co., Ltd., Beijing, China), acetonitrile (Sinopharm Chemical Reagent Co., Ltd., Beijing, China), ethyl alcohol (Beihua Fine Chemicals Co., Ltd., Beijing, China), and ammonia (25\%, Beihua Fine Chemicals Co., Ltd., Beijing, China) were purchased from a local supplier and were reagents of analytical grade. All the solutions were freshly prepared using deionized water. In addition, a crude oil sample with a density of $0.895 \mathrm{~g} / \mathrm{cm}^{3}$ and a viscosity of $15.2 \mathrm{mPa} \cdot \mathrm{s}\left(45^{\circ} \mathrm{C}\right)$, and eight cores with lengths of $5.0 \mathrm{~cm}$ and diameters of $2.5 \mathrm{~cm}$ were obtained from a Daqing oil reservoir for 
the displacement experiments. The synthetic formation water used for the displacement experiments was a brine with a total dissolved solids (TDS) value of $5380 \mathrm{mg} / \mathrm{L}$.

\subsection{Synthesis of $\mathrm{SiO}_{2}$ Nanoparticles}

$\mathrm{SiO}_{2}$ nanoparticles were synthesized by a Stöber process [44]. Briefly, TEOS (11.2 mL), ethyl alcohol $(84.1 \mathrm{~mL})$, and deionized water $(17.1 \mathrm{~mL})$ were added into a $250 \mathrm{~mL}$ conical flask. After that, ammonia $(4.76 \mathrm{~mL})$ was poured into the above solution under continuous magnetic stirring. After the solution was allowed to react for $6 \mathrm{~h}$ under magnetic stirring, the $\mathrm{SiO} 2$ nanoparticles were obtained by being centrifuged, washed with ethanol, and dried at $70^{\circ} \mathrm{C}$ for $8 \mathrm{~h}$ in a vacuum.

\subsection{Synthesis of $\mathrm{SiO}_{2} / \mathrm{P}(\mathrm{MBAAm-co}-A \mathrm{M})$ Polymeric Nanoparticles}

$\mathrm{SiO}_{2} / \mathrm{P}(\mathrm{MBAAm}-\mathrm{co}-\mathrm{AM})$ polymeric nanoparticles were synthesized by a distillation- precipitation polymerization method [45]. Briefly, the as-prepared $\mathrm{SiO}_{2}$ nanoparticles $(0.5 \mathrm{~g})$ were suspended in acetonitrile $(40 \mathrm{~mL})$ in a $250 \mathrm{~mL}$ three-neck flask connected to a reflux condenser. MBAA $(0.2 \mathrm{~g})$ and AM (0.5 g) were dissolved in the above suspension and sonicated for $10 \mathrm{~min}$ at room temperature. Then, AIBN ( $0.1 \mathrm{~g})$ was added into the above system and the mixture was sonicated for 5 min. After that, the above mixture was reacted at $90^{\circ} \mathrm{C}$ for $15 \mathrm{~min}$ and then distilled at $115^{\circ} \mathrm{C}$ for $90 \mathrm{~min}$ with a reflux ratio of 2 until all solvents were distilled out. The products were dissolved in ethyl alcohol and sonicated for $10 \mathrm{~min}$. Finally, $\mathrm{SiO}_{2} / \mathrm{P}(\mathrm{MBAAm}-\mathrm{co}-\mathrm{AM})$ polymeric nanoparticles were obtained after being centrifuged, washed with deionized water, and dried at $50{ }^{\circ} \mathrm{C}$ for $12 \mathrm{~h}$ in a vacuum.

\subsection{Characterization}

Scanning electron microscopy (SEM, S-4500 Hitachi, Tokyo, Japan) and transmission electron microscopy (TEM, JEM-200CX JEOL, Tokyo, Japan) were employed to characterize the morphology of the samples. The functional groups of the products were characterized via Fourier-transform infrared spectroscopy (FT-IR, Nexus 670 Thermo Nicolet, Wisconsin, USA). The thermogravimetric analysis (TGA) of the products was performed on a thermogravimetric analyzer (SDT Q600 TA, New Castle, $\mathrm{DE}, \mathrm{USA})$ at a heating rate of $10^{\circ} \mathrm{C} / \mathrm{min}$ in nitrogen.

\subsection{Particle Size Distribution Measurements}

$\mathrm{SiO}_{2} / \mathrm{P}(\mathrm{MBAAm}-\mathrm{co}-\mathrm{AM})$ polymeric nanoparticles can mixed with water to form a suspension. In suspension, these polymeric nanoparticles can absorb water, and swell with their diameters increasing from their original nano size or submicron size to micron size. Thus, particle size distribution measurements were carried out by dynamic light scattering (DLS), using a laser particle size analyzer (Mastersizer 2000 Malvern, Worcestershire, UK). The particle size distribution curves of $\mathrm{SiO}_{2} / \mathrm{P}(\mathrm{MBAAm}-\mathrm{co}-\mathrm{AM})$ polymeric nanoparticles were determined at various swelling times in suspension with a salinity of $5.0 \mathrm{~g} / \mathrm{L}$ at $40{ }^{\circ} \mathrm{C}$. Medium diameters of polymeric nanoparticles at various swelling times were obtained by analyzing the particle size distribution curves. Then, the swelling property was quantificationally described by the swelling ratio, defined as follows:

$$
Q=\frac{D_{2}-D_{1}}{D_{1}}
$$

where $Q$ is the swelling ratio, $D_{2}$ is the medium diameter of swollen polymeric nanoparticles at each time interval $(\mu \mathrm{m})$, and $D_{1}$ is the average particle diameter of initial dry composite nanoparticles $(\mu \mathrm{m})$.

\subsection{Viscosity Measurements}

The viscosity measurements were carried out using a viscometer (LV-DV2T Brookfield, Middleboro, MA, USA). The apparent viscosities of the $\mathrm{SiO}_{2} / \mathrm{P}(\mathrm{MBAAm}-\mathrm{co}-\mathrm{AM})$ suspensions were measured at a shear rate of $7.34 \mathrm{~s}^{-1}$ to investigate the effect of mass concentration, temperature, salinity, and swelling 
time. The apparent viscosities of the $\mathrm{SiO}_{2} / \mathrm{P}(\mathrm{MBAAm}-\mathrm{co}-\mathrm{AM})$ suspensions versus shear rates were determined at mass concentrations of $0.05,0.5$, and $1.5 \mathrm{~g} / \mathrm{L}$, temperatures of 40,60 , and $80{ }^{\circ} \mathrm{C}$, salinities of 2,5 , and $10 \mathrm{~g} / \mathrm{L}$, and swelling times of 24,120 , and $240 \mathrm{~h}$.

\subsection{Oil Displacement Experiments}

Before starting the flooding experiments, cores were properly cleaned and dried at $150{ }^{\circ} \mathrm{C}$ for $72 \mathrm{~h}$. Their porosity was measured using the weight method, and permeability measurements were conducted using Darcy's law. In each flood test, the core was first saturated with brine, then mounted in hydrostatic core holders at a confining pressure of $3 \mathrm{MPa}$; finally, the samples were flooded with crude oil at a constant injection rate of $0.2 \mathrm{~mL} / \mathrm{min}$ until the condition of irreducible water saturation was achieved in core. The flood experiments were carried out at $45^{\circ} \mathrm{C}$. The core was aged for $48 \mathrm{~h}$ to achieve the wettability state at $45^{\circ} \mathrm{C}$. After that, the core sample was flooded with brine at a flow rate of $0.2 \mathrm{~mL} / \mathrm{min}$ until the water cut was about $98 \%$. Subsequently, a chemical slug of suspension prepared by mixing $1.5 \mathrm{~g} \mathrm{SiO}_{2} / \mathrm{P}(\mathrm{MBAAm}-\mathrm{co}-\mathrm{AM})$ polymeric nanoparticles with $1 \mathrm{~L}$ of water was injected at a constant injection rate of $0.2 \mathrm{~mL} / \mathrm{min}$, followed by an extended waterflood at the same flow rate until the oil production stopped. The recovered crude oil and brine were collected in fluid collectors, and the injection pressure data were recorded. The experimental set-up used for the core-flooding experiments is shown in Figure 2.

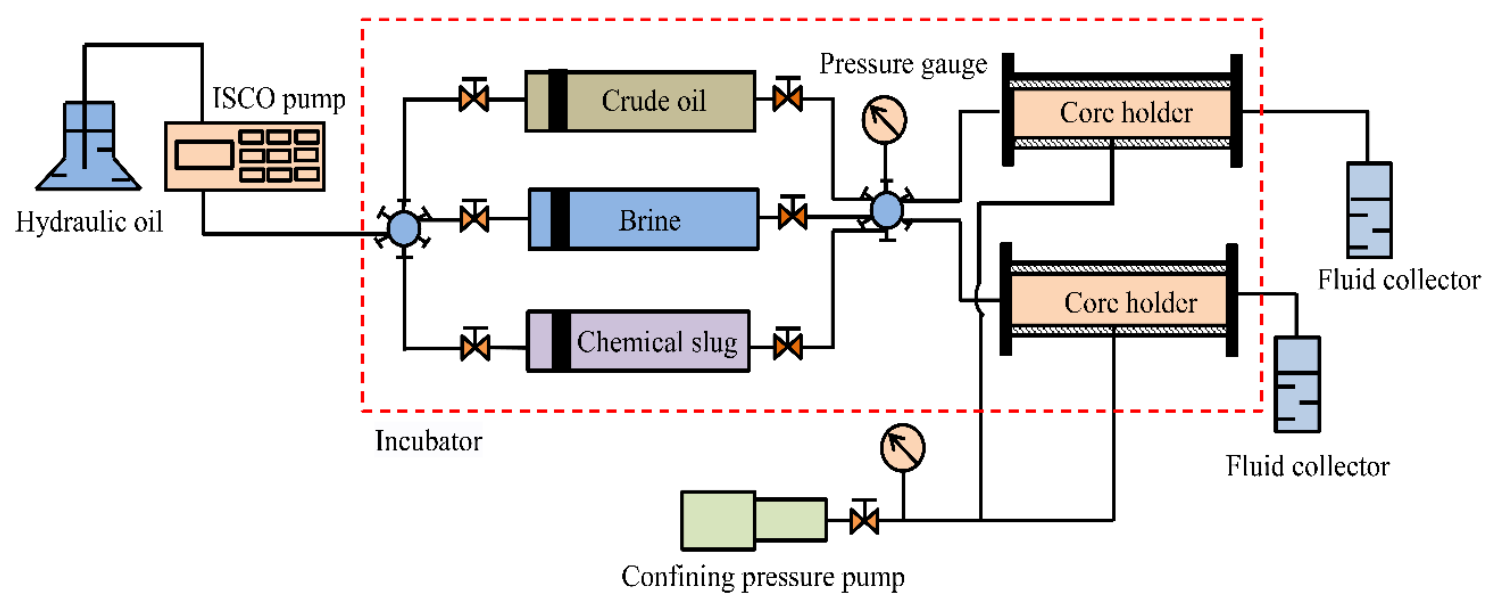

Figure 2. Schematic of the experimental set-up. The experimental set-up consisted of two hydrostatic core holders, a pump to maintain confining pressure, a displacement pump for the flooding agent, and two fluid accumulators for holding the collected oil sample, brine, and chemical slug.

\section{Results and Discussion}

\subsection{Characterization of $\mathrm{SiO}_{2} / \mathrm{P}(\mathrm{MBAAm-co-AM})$ Nanoparticles}

The size, shape, and surface morphologies of $\mathrm{SiO}_{2}$ and $\mathrm{SiO}_{2} / \mathrm{P}(\mathrm{MBAAm}-\mathrm{co}-\mathrm{AM})$ nanoparticles were characterized by SEM and TEM, as shown in Figure 3. It was found from Figure $3 \mathrm{a}$ that $\mathrm{SiO}_{2}$ nanoparticles are spherical and uniform, and are approximately $200 \mathrm{~nm}$ in diameter. The TEM image (Figure 3b) indicates that $\mathrm{SiO}_{2} / \mathrm{P}(\mathrm{MBAAm}-\mathrm{co}-\mathrm{AM})$ nanoparticles still retain their spherical morphologies, and consist of $\mathrm{a} \mathrm{SiO}_{2}$ core and a shell of polymer, with diameters ranging from 200 to $400 \mathrm{~nm}$. The thickness of the polymer layer is in the range of 50-100 nm. Thus, it can be considered that $\mathrm{SiO}_{2} / \mathrm{P}(\mathrm{MBAAm}-\mathrm{co}-\mathrm{AM})$ nanoparticles were successfully synthesized. 


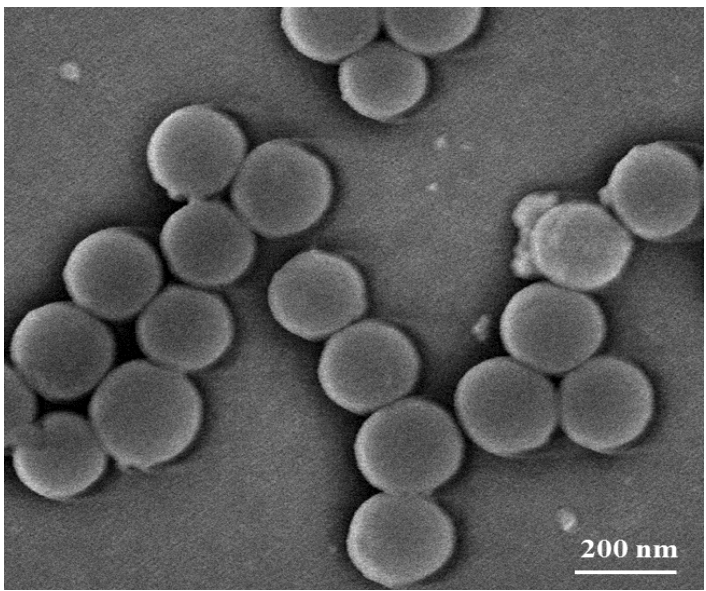

(a)

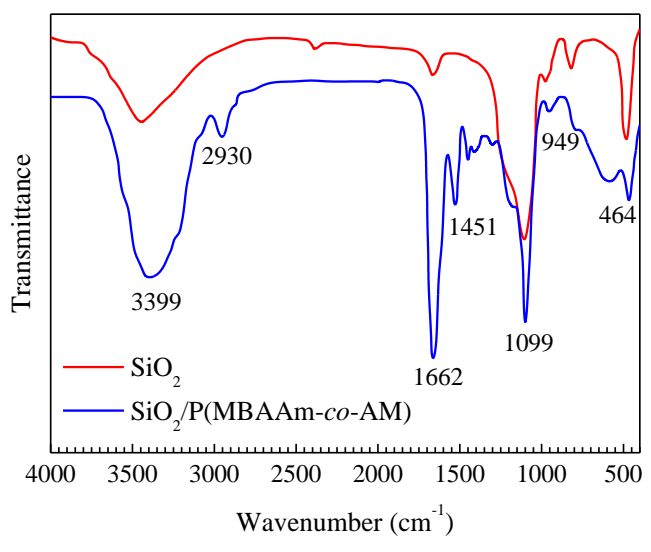

(c)

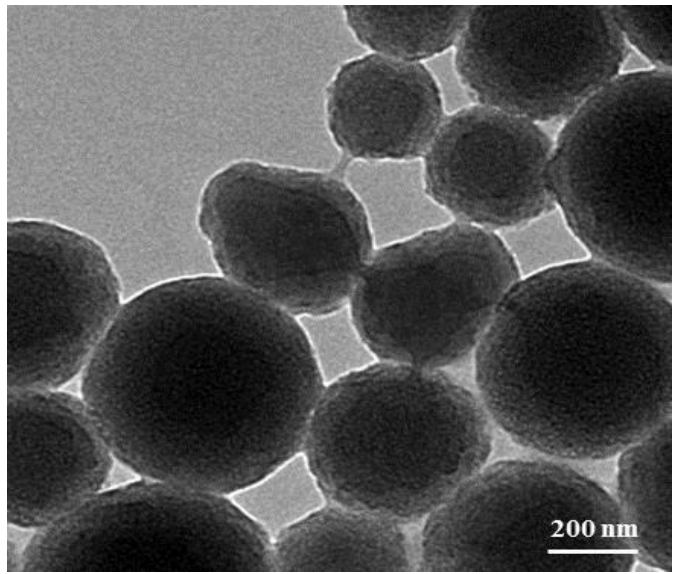

(b)

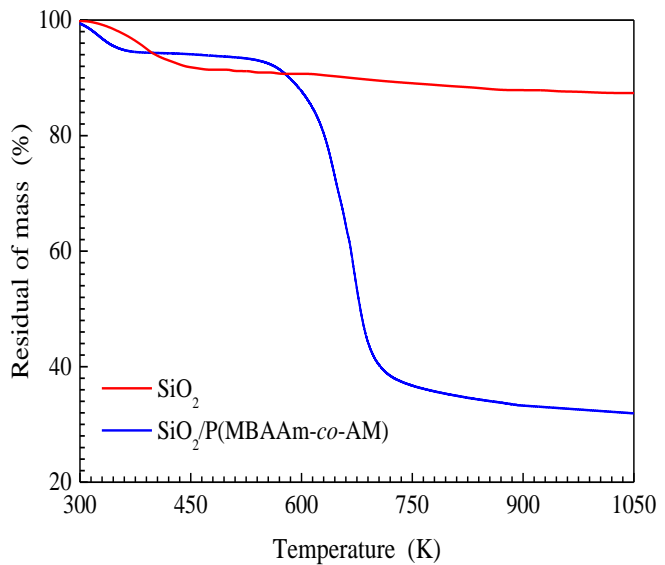

(d)

Figure 3. $\mathrm{SEM}$ image of $\mathrm{SiO}_{2}$ nanoparticles (a); $\mathrm{TEM}$ image of $\mathrm{SiO}_{2} / \mathrm{P}(\mathrm{MBAAm}-\mathrm{co}-\mathrm{AM})$ nanoparticles (b); and FT-IR spectra (c) and TGA curves (d) of $\mathrm{SiO}_{2}, \mathrm{SiO}_{2} / \mathrm{P}(\mathrm{MBAAm}-\mathrm{co}-\mathrm{AM})$.

Figure 3c shows the FT-IR spectra of $\mathrm{SiO}_{2}$ and $\mathrm{SiO}_{2} / \mathrm{P}(\mathrm{MBAAm}-\mathrm{co}-\mathrm{AM})$. The peaks at 3415, 1099, 957,806 , and $464 \mathrm{~cm}^{-1}$ are the characteristic peaks of $\mathrm{SiO}_{2}$ [46]. The peaks at 3732 and $1641 \mathrm{~cm}^{-1} \mathrm{may}^{-}$ be due to the vibration of water molecules [47]. As seen in the spectrum of $\mathrm{SiO}_{2} / \mathrm{P}(\mathrm{MBAAm}-\mathrm{co}-\mathrm{AM})$, the peaks at 1099 and $949 \mathrm{~cm}^{-1}$ are assigned as the characteristic peaks of $\mathrm{SiO}_{2}$, and associated with the symmetric stretching vibration of the $\mathrm{Si}-\mathrm{O}-\mathrm{Si}$ bond and the stretching vibration of the Si-OH bond, respectively [48]. The peaks at 3399 and $1662 \mathrm{~cm}^{-1}$ are attributed to the stretching vibration of the $\mathrm{N}-\mathrm{H}$ bond and the $\mathrm{C}=\mathrm{O}$ bond in the amide group, respectively [49]. The peaks at 2930 and $1451 \mathrm{~cm}^{-1}$ are ascribed to the stretching vibration of the $\mathrm{C}-\mathrm{H}$ bond and the bending vibration of the $\mathrm{C}-\mathrm{H}$ bond in the saturated alkyl group, respectively [50]. Therefore, this spectrum demonstrates the successful preparation of $\mathrm{SiO}_{2} / \mathrm{P}(\mathrm{MBAAm}-\mathrm{co}-\mathrm{AM})$ nanoparticles as well.

Figure $3 \mathrm{~d}$ shows the TGA curves of $\mathrm{SiO}_{2}$ and $\mathrm{SiO}_{2} / \mathrm{P}(\mathrm{MBAAm}-\mathrm{co}-\mathrm{AM})$. The weight losses of $\mathrm{SiO}_{2}$ and $\mathrm{SiO}_{2} / \mathrm{P}(\mathrm{MBAAm}-\mathrm{co}-\mathrm{AM})$ prior to reaching $458 \mathrm{~K}$ are attributed to the loss of adsorbed water [51]. $\mathrm{SiO}_{2}$ shows a small degradation (a loss of $4.26 \%$ ) between 458 and $1050 \mathrm{~K}$. The TGA curve of $\mathrm{SiO}_{2} / \mathrm{P}(\mathrm{MBAAm}-\mathrm{co}-\mathrm{AM})$ shows three steps. The first step occurs at $300-458 \mathrm{~K}$ due to a $6.02 \%$ loss, which is attributed to the loss of physisorbed water. The second and third steps are at $458-737 \mathrm{~K}$ and at $737-1050 \mathrm{~K}$, with losses of $56.67 \%$ and $6.52 \%$, respectively. These are ascribed to the loss from 
polymer pyrolysis and dehydroxylation from $\mathrm{SiO}_{2}$, respectively [52]. According to the total loss of $\mathrm{SiO}_{2} / \mathrm{P}(\mathrm{MBAAm}-\mathrm{co}-\mathrm{AM})$, about $56.67 \%$ of $\mathrm{P}(\mathrm{MBAAm}-\mathrm{co}-\mathrm{AM})$ was grafted on the surface of $\mathrm{SiO}_{2}$, and the residue is about $30.79 \%$ of $\mathrm{SiO}_{2}$. These results further demonstrate the successful preparation of $\mathrm{P}(\mathrm{MBAAm}-\mathrm{co}-\mathrm{AM})$ grafted on the surface of $\mathrm{SiO}_{2}$.

\subsection{Swelling Performances of $\mathrm{SiO}_{2} / \mathrm{P}(M B A A m-c o-A M)$ Nanoparticles in a Suspension}

An SEM image of a $\mathrm{SiO}_{2} / \mathrm{P}(\mathrm{MBAAm}-\mathrm{co}-\mathrm{AM})$ suspension swollen for $24 \mathrm{~h}$ at $5000 \mathrm{mg} / \mathrm{L}$ is shown in Figure 4a. In this suspension, the size of the $\mathrm{SiO}_{2} / \mathrm{P}(\mathrm{MBAAm}-\mathrm{co}-\mathrm{AM})$ nanoparticles is obviously larger than that of their dry samples. The size of a single $\mathrm{SiO}_{2} / \mathrm{P}(\mathrm{MBAAm}-\mathrm{co}-\mathrm{AM})$ nanoparticle is between 250 and $1000 \mathrm{~nm}$, and some nanoparticles are agglomerated in the high concentration of the $\mathrm{SiO}_{2} / \mathrm{P}(\mathrm{MBAAm}-\mathrm{co}-\mathrm{AM})$ suspension. The agglomerated nanoparticles range in size from 800 to $1500 \mathrm{~nm}$. This result proves that $\mathrm{SiO}_{2} / \mathrm{P}(\mathrm{MBAAm}-\mathrm{co}-\mathrm{AM})$ nanoparticles can absorb water to swell in aqueous solution. In addition, a Mastersizer 2000 laser particle size analyzer was used in this study to provide more details about $\mathrm{SiO}_{2} / \mathrm{P}(\mathrm{MBAAm}-\mathrm{co}-\mathrm{AM})$ nanoparticles in a suspension.

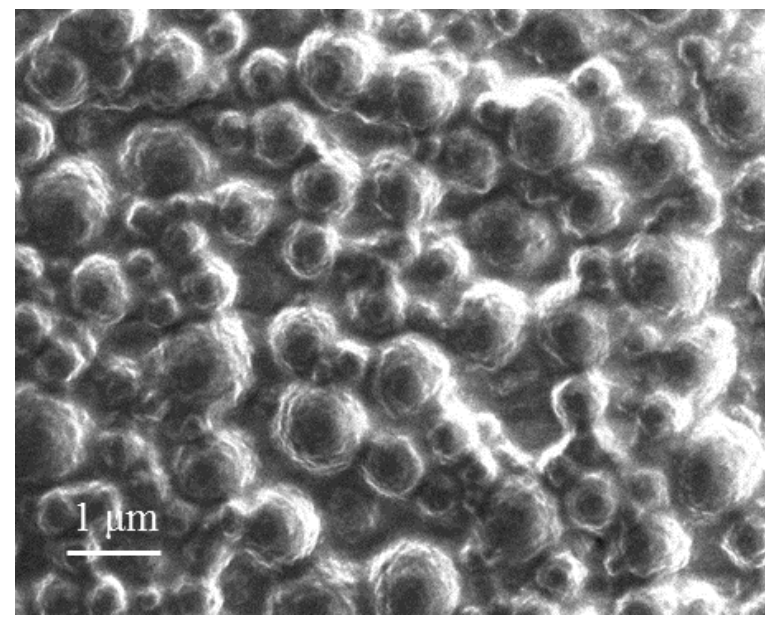

(a)

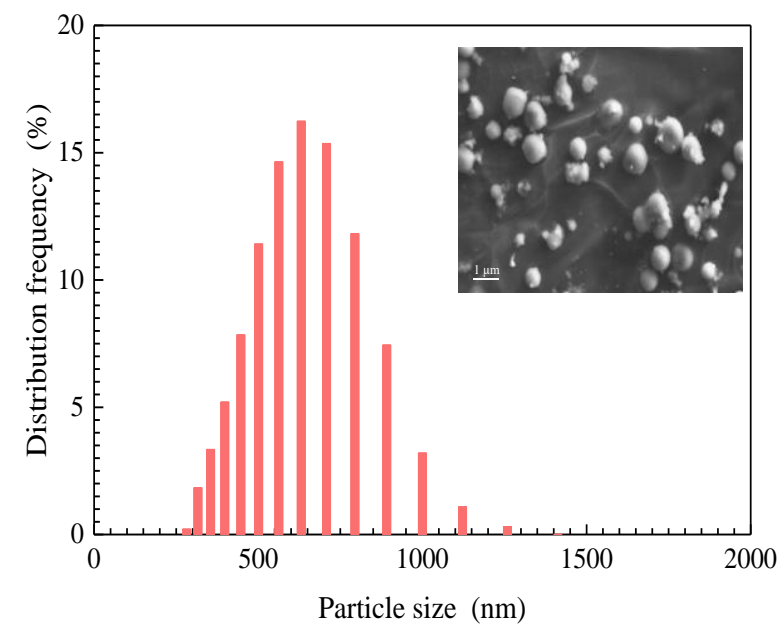

(c)

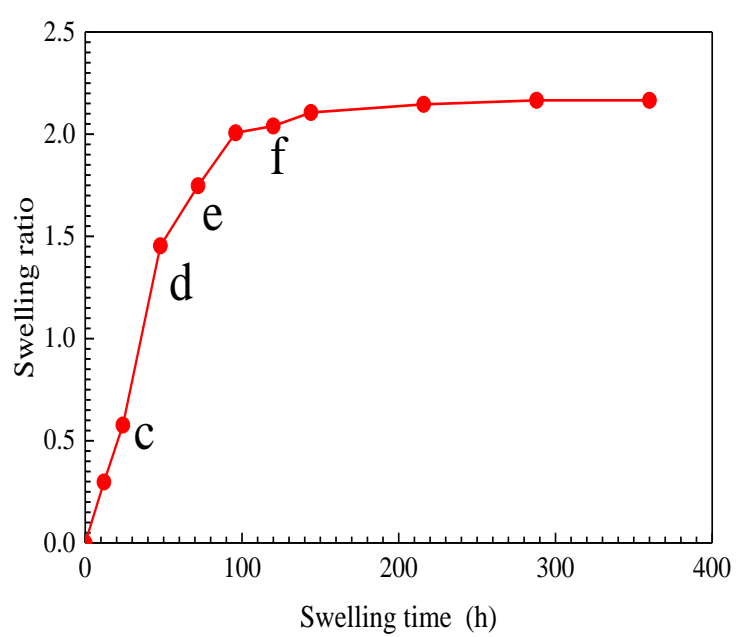

(b)

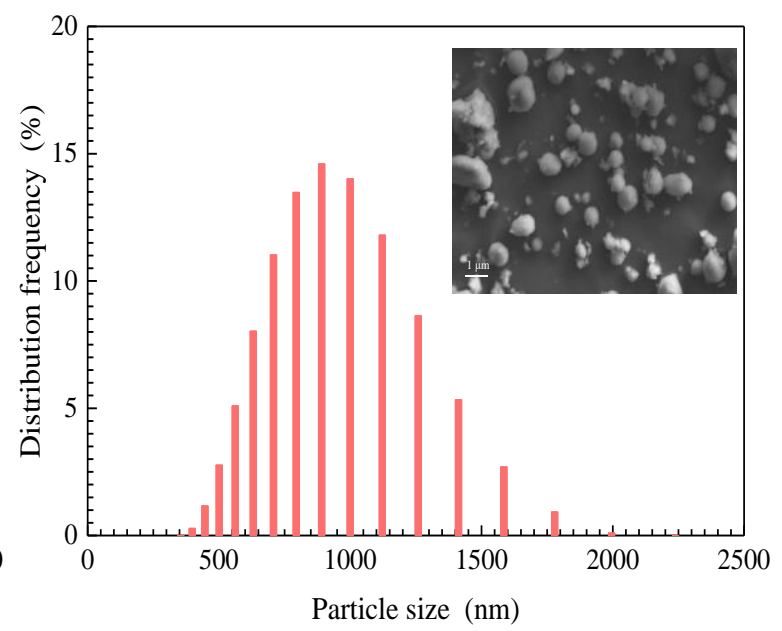

(d)

Figure 4. Cont. 


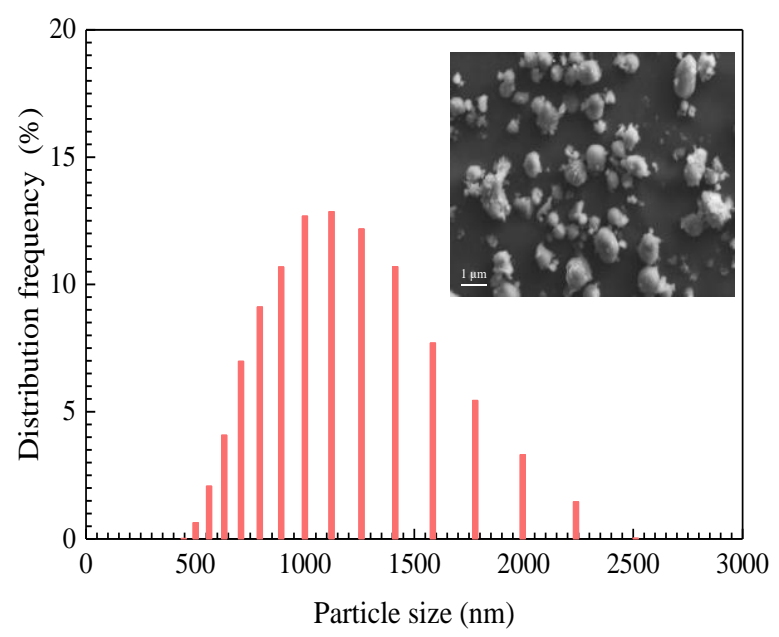

(e)

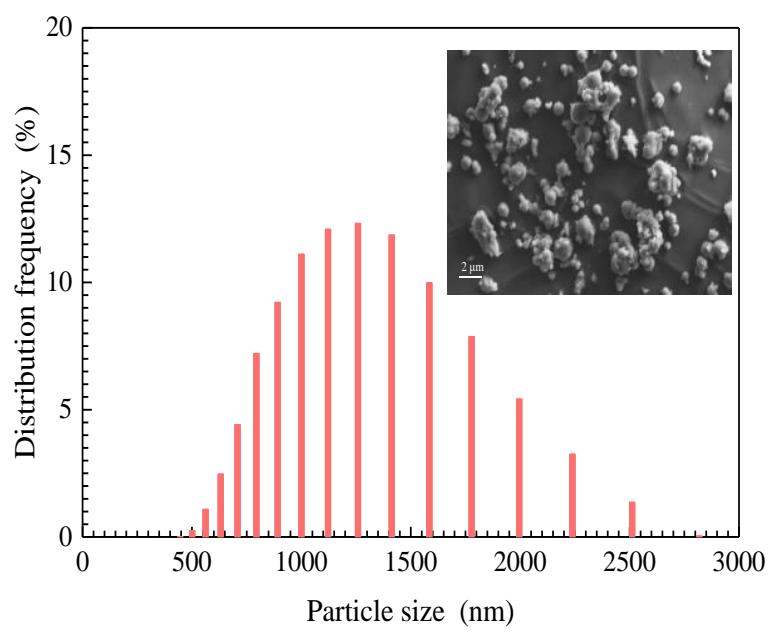

(f)

Figure 4. $\mathrm{SEM}$ image of $\mathrm{SiO}_{2} / \mathrm{P}(\mathrm{MBAAm}-\mathrm{co}-\mathrm{AM})$ suspension (a); the effect of swelling time on swelling ratio of $\mathrm{SiO}_{2} / \mathrm{P}(\mathrm{MBAAm}-\mathrm{co}-\mathrm{AM})$ nanoparticles $(\mathbf{b}$, total dissolved solids (TDS) $=5 \mathrm{~g} / \mathrm{L}$, $\left.\mathrm{T}=40^{\circ} \mathrm{C}\right)$; and particle size distribution curves of $\mathrm{SiO}_{2} / \mathrm{P}(\mathrm{MBAAm}-\mathrm{co}-\mathrm{AM})$ nanoparticles in suspension at swelling times of $24 \mathrm{~h}(\mathbf{c}), 48 \mathrm{~h}(\mathbf{d}), 72 \mathrm{~h}(\mathbf{e})$, and $120 \mathrm{~h}(\mathbf{f})$. Insets are the SEM images of $\mathrm{SiO}_{2} / \mathrm{P}(\mathrm{MBAAm}-\mathrm{co}-\mathrm{AM})$ suspension.

The plot of the swelling ratio of the $\mathrm{SiO}_{2} / \mathrm{P}(\mathrm{MBAAm}-\mathrm{co}-\mathrm{AM})$ nanoparticles versus swelling time, at $1500 \mathrm{mg} / \mathrm{L}$, is shown in Figure $4 \mathrm{~b}$. The swelling ratio of $\mathrm{SiO}_{2} / \mathrm{P}(\mathrm{MBAAm}-\mathrm{co}-\mathrm{AM})$ nanoparticles swiftly increases at the initial stage and then slows until the swelling reaches equilibrium. Under this experimental condition, the equilibrium swelling ratio of $\mathrm{SiO}_{2} / \mathrm{P}(\mathrm{MBAAm}-\mathrm{co}-\mathrm{AM})$ nanoparticles can reach up to about 2 .

The particle size distribution curves of $\mathrm{SiO}_{2} / \mathrm{P}(\mathrm{MBAAm}-\mathrm{co}-\mathrm{AM})$ nanoparticles at swelling times of 24, 48, 72, and $120 \mathrm{~h}$ were determined, as shown in Figure 4c-f. It was found that the particle size distribution curves approximately match the normal distribution. A shift of particle size distributions to larger sizes occurs with an increase of swelling time, with a concomitant decrease of the height of the predominant peak in volume distribution. As swelling time increases from 24 to $120 \mathrm{~h}$, the particle size with the largest distribution frequency increases from 631 to $1258 \mathrm{~nm}$, with a decrease of distribution frequency from 16.24 to $12.32 \%$. SEM images of $\mathrm{SiO}_{2} / \mathrm{P}(\mathrm{MBAAm}-\mathrm{co}-\mathrm{AM})$ suspension, shown as the insets in Figure $4 \mathrm{c}-\mathrm{f}$, qualitatively reflect both the swelling process and change regulation of $\mathrm{SiO}_{2} / \mathrm{P}(\mathrm{MBAAm}-\mathrm{co}-\mathrm{AM})$ nanoparticles in water.

\subsection{Rheological Behaviors of $\mathrm{SiO}_{2} / \mathrm{P}(\mathrm{MBAAm-co-AM)}$ Suspension}

The apparent viscosity of the $\mathrm{SiO}_{2} / \mathrm{P}(\mathrm{MBAAm}-\mathrm{co}-\mathrm{AM})$ suspension versus mass concentration of $\mathrm{SiO}_{2} / \mathrm{P}(\mathrm{MBAAm}-\mathrm{co}-\mathrm{AM})$ nanoparticles is shown in Figure 5a. As shown, at a higher mass concentration, the $\mathrm{SiO}_{2} / \mathrm{P}(\mathrm{MBAAm}-\mathrm{co}-\mathrm{AM})$ suspension exhibits a larger apparent viscosity. This is because with increasing mass concentration, the number of $\mathrm{SiO}_{2} / \mathrm{P}(\mathrm{MBAAm}-\mathrm{co}-\mathrm{AM})$ nanoparticle collisions with water molecules increases, which results in an increase of apparent viscosity [53].

The apparent viscosity of the $\mathrm{SiO}_{2} / \mathrm{P}(\mathrm{MBAAm}-\mathrm{co}-\mathrm{AM})$ suspension versus temperature is shown in Figure $5 b$. According to Figure $5 b$, the apparent viscosity of the $\mathrm{SiO}_{2} / \mathrm{P}(\mathrm{MBAAm}-\mathrm{co}-\mathrm{AM})$ suspension decreases with increasing temperature. As the temperature rises, it reduces the intermolecular force, so the $\mathrm{SiO}_{2} / \mathrm{P}(\mathrm{MBAAm}-\mathrm{co}-\mathrm{AM})$ suspension moves more easily, leading to a decrease of apparent viscosity.

Figure $5 \mathrm{c}$ shows the apparent viscosity of the $\mathrm{SiO}_{2} / \mathrm{P}(\mathrm{MBAAm}-\mathrm{co}-\mathrm{AM})$ suspension as a function of the salinity. As shown in Figure 5c, the apparent viscosity of the $\mathrm{SiO}_{2} / \mathrm{P}(\mathrm{MBAAm}-\mathrm{co}-\mathrm{AM})$ suspension decreases with an increase of salinity. This means that with an increase of salinity, the particle size of the swollen nanoparticles decreases to reduce the number of nanoparticles collisions with water molecules, resulting in a decrease of apparent viscosity [54]. 
Figure $5 \mathrm{~d}$ shows the apparent viscosity of the $\mathrm{SiO}_{2} / \mathrm{P}(\mathrm{MBAAm}-\mathrm{co}-\mathrm{AM})$ suspension as a function of the swelling time. The apparent viscosity of the $\mathrm{SiO}_{2} / \mathrm{P}(\mathrm{MBAAm}-\mathrm{co}-\mathrm{AM})$ suspension rapidly increases at the initial stage and then slowly increases until the apparent viscosity remains constant at swelling times greater than $200 \mathrm{~h}$. With an increase of swelling time, $\mathrm{SiO}_{2} / \mathrm{P}(\mathrm{MBAAm}-\mathrm{co}-\mathrm{AM})$ nanoparticles swell to enlarge their particle sizes, so the number of nanoparticles that collide with water molecules increases, resulting in an increase of apparent viscosity. However, when the swelling reaches equilibrium, the particle size does not enlarge, and the number of collisions with water molecules does not increase, so the apparent viscosity remains constant.

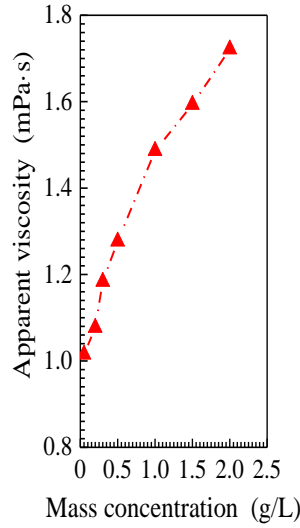

(a)

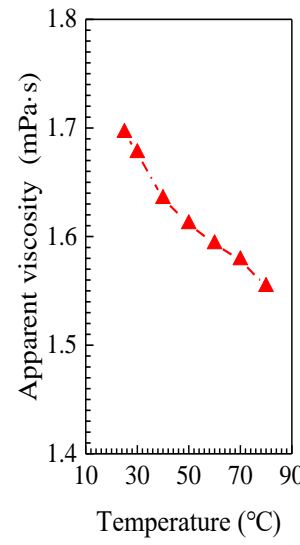

(b)

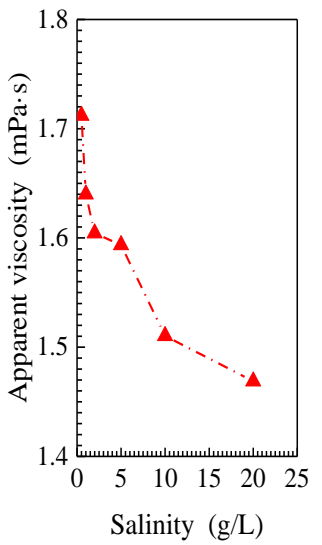

(c)

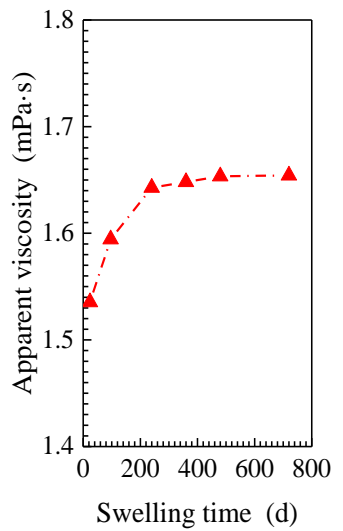

(d)

Figure 5. Effect of mass concentration $\left(\mathbf{a}, \mathrm{T}=60^{\circ} \mathrm{C}, \mathrm{TDS}=5 \mathrm{~g} / \mathrm{L}\right.$, and $\left.\mathrm{t}=120 \mathrm{~h}\right)$, temperature $(\mathbf{b}, \mathrm{C}=1.5 \mathrm{~g} / \mathrm{L}$, TDS $=5 \mathrm{~g} / \mathrm{L}$, and $\mathrm{t}=120 \mathrm{~h})$, salinity $\left(\mathrm{c}, \mathrm{T}=60^{\circ} \mathrm{C}, \mathrm{C}=1.5 \mathrm{~g} / \mathrm{L}\right.$, and $\left.\mathrm{t}=120 \mathrm{~h}\right)$, and swelling time $\left(\mathrm{d}, \mathrm{T}=60^{\circ} \mathrm{C}\right.$, $\mathrm{C}=1.5 \mathrm{~g} / \mathrm{L}$, and TDS $=5 \mathrm{~g} / \mathrm{L})$ on viscosity properties of $\mathrm{SiO}_{2} / \mathrm{P}(\mathrm{MBAAm}-\mathrm{co}-\mathrm{AM})$ suspension.

The apparent viscosities of the $\mathrm{SiO}_{2} / \mathrm{P}(\mathrm{MBAAm}-\mathrm{co}-\mathrm{AM})$ suspension with respect to shear rate are presented in Figure 6 at various mass concentrations of $\mathrm{SiO}_{2} / \mathrm{P}(\mathrm{MBAAm}-\mathrm{co}-\mathrm{AM})$ nanoparticles, temperatures, salinities, and swelling times. Under all experimental conditions, the apparent viscosity of the $\mathrm{SiO}_{2} / \mathrm{P}(\mathrm{MBAAm}-\mathrm{co}-\mathrm{AM})$ suspension versus shear rate follows a similar trend. At lower shear rates, the apparent viscosity of the $\mathrm{SiO}_{2} / \mathrm{P}(\mathrm{MBAAm}-\mathrm{co}-\mathrm{AM})$ suspension decreases with an increase of shear rate, and we can consider the behavior of the $\mathrm{SiO}_{2} / \mathrm{P}(\mathrm{MBAAm}-\mathrm{co}-\mathrm{AM})$ suspension as non-Newtonian. At shear rates greater than $300 \mathrm{~s}^{-1}$, the constant apparent viscosity of the $\mathrm{SiO}_{2} / \mathrm{P}(\mathrm{MBAAm}-\mathrm{co}-\mathrm{AM})$ suspension after changing shear rate indicates that the apparent viscosity does not depend on shear rate and represents Newtonian fluid behavior.

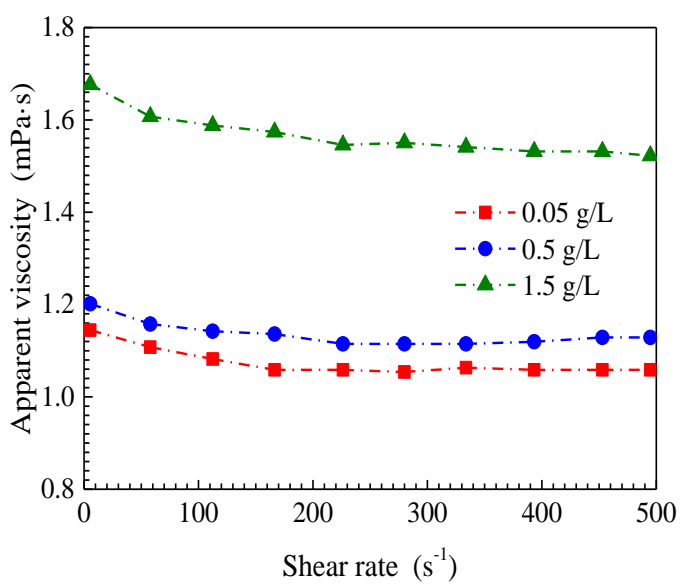

(a)

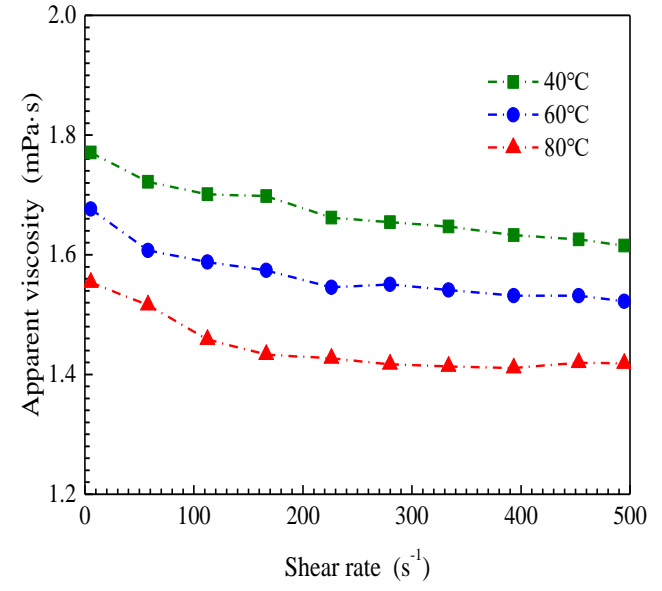

(b)

Figure 6. Cont. 


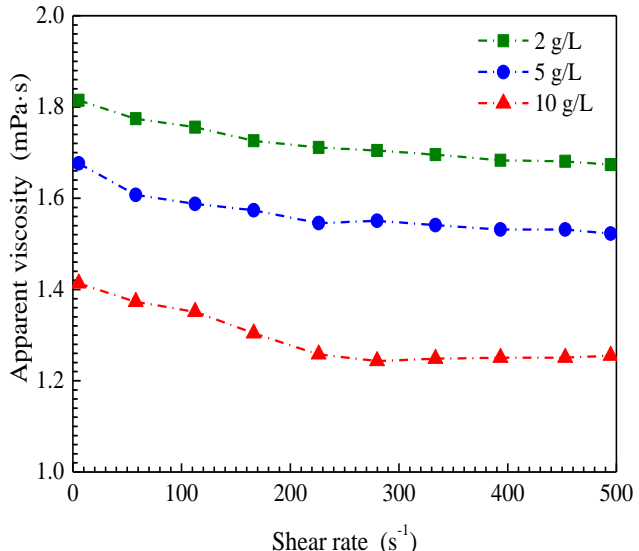

(c)

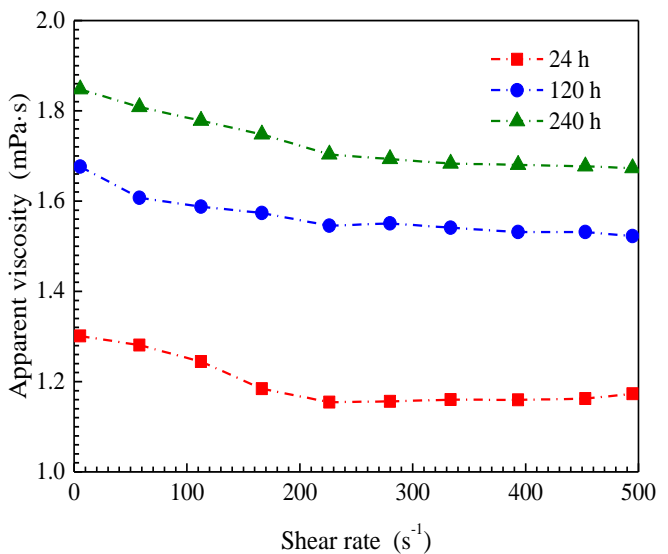

(d)

Figure 6. Effect of mass concentration $\left(\mathbf{a}, \mathrm{T}=60^{\circ} \mathrm{C}, \mathrm{TDS}=5 \mathrm{~g} / \mathrm{L}\right.$, and $\left.\mathrm{t}=120 \mathrm{~h}\right)$, temperature $(\mathbf{b}, \mathrm{C}=1.5 \mathrm{~g} / \mathrm{L}$, TDS $=5 \mathrm{~g} / \mathrm{L}$, and $\mathrm{t}=120 \mathrm{~h})$, salinity $\left(\mathrm{c}, \mathrm{T}=60^{\circ} \mathrm{C}, \mathrm{C}=1.5 \mathrm{~g} / \mathrm{L}\right.$, and $\left.\mathrm{t}=120 \mathrm{~h}\right)$, and swelling time $\left(\mathrm{d}, \mathrm{T}=60^{\circ} \mathrm{C}\right.$, $\mathrm{C}=1.5 \mathrm{~g} / \mathrm{L}$, and TDS $=5 \mathrm{~g} / \mathrm{L})$ on rheological properties of $\mathrm{SiO}_{2} / \mathrm{P}(\mathrm{MBAAm}-c o-\mathrm{AM})$ suspension.

\subsection{EOR by a $\mathrm{SiO}_{2} / \mathrm{P}(\mathrm{MBAAm-co}-\mathrm{AM})$ Suspension in Parallel Cores}

$\mathrm{SiO}_{2} / \mathrm{P}(\mathrm{MBAAm}-\mathrm{co}-\mathrm{AM})$ composite nanoparticles were mixed with water to form a $\mathrm{SiO}_{2} /$ $\mathrm{P}(\mathrm{MBAAm}-\mathrm{co}-\mathrm{AM})$ suspension. The concentration of $\mathrm{SiO}_{2} / \mathrm{P}(\mathrm{MBAAm}-\mathrm{co}-\mathrm{AM})$ composite nanoparticles was $1500 \mathrm{mg} / \mathrm{L}$. Parallel cores flooding tests were carried out to investigate the efficiency of $\mathrm{SiO}_{2} / \mathrm{P}(\mathrm{MBAAm}-\mathrm{co}-\mathrm{AM})$ suspension in EOR in heterogeneous low-permeability reservoirs. Core parameters and test results are shown in Table 1 . In four tests, the slug size of a $\mathrm{SiO}_{2} / \mathrm{P}(\mathrm{MBAAm}-\mathrm{co}-\mathrm{AM})$ suspension was $0.5 \mathrm{PV}$ (pore volume) and the permeability ratio of parallel cores ranged from 1.40 to 15.49 .

Table 1. Efficiency of enhanced oil recovery (EOR) in heterogeneous parallel cores.

\begin{tabular}{cccccc}
\hline Test & $\begin{array}{c}\text { Permeability } \\
\left(\mathbf{1 0}^{-\mathbf{3}} \boldsymbol{\mu m}^{\mathbf{2}}\right.\end{array}$ & $\begin{array}{c}\text { Permeability } \\
\text { Ratio }\end{array}$ & $\begin{array}{c}\text { Recovery of } \\
\text { Brine Flood (\%) }\end{array}$ & $\begin{array}{c}\text { Final Oil } \\
\text { Recovery (\%) }\end{array}$ & $\begin{array}{c}\text { Incremental Oil } \\
\text { Recovery (\%) }\end{array}$ \\
\hline \multirow{2}{*}{1} & High 20.28 & \multirow{2}{*}{1.40} & 52.37 & 56.98 & 4.61 \\
& Low 14.47 & & 46.70 & 54.39 & 7.69 \\
2 & High 75.82 & 4.36 & 53.84 & 58.82 & 4.98 \\
& Low 17.39 & & 29.79 & 46.06 & 16.27 \\
\multirow{2}{*}{3} & High 66.45 & \multirow{2}{*}{8.28} & 55.49 & 61.74 & 6.25 \\
& Low 8.03 & & 22.99 & 41.57 & 18.58 \\
4 & High 64.74 & \multirow{2}{*}{15.49} & 56.69 & 65.15 & 8.46 \\
& Low 4.18 & & 17.61 & 41.22 & 23.61 \\
\hline
\end{tabular}

\subsubsection{Effect of Permeability Ratio on Fractional Flows}

The fractional flow curves of three flooding stages, which included an initial brine flood, a $\mathrm{SiO}_{2} / \mathrm{P}(\mathrm{MBAAm}-\mathrm{co}-\mathrm{AM})$ suspension slug injection, and an extended brine flood in four parallel cores tests, are plotted in Figure 7. As shown in Figure 7, the same changes of fractional flow curves are observed in four flooding tests of different permeability ratios. In the initial brine flood stage, the fractional flows in high-permeability cores increase with injection, while the fractional flows in low-permeability cores decrease with injection. Moreover, the difference of fractional flows in high- and low-permeability cores increase as brines are injected. After brine breaks through in high-permeability cores, brine flooding mainly passes through high-permeability cores. Therefore, at the end of brine flooding, the fractional flows in high-permeability cores are greater than $90 \%$, and in low-permeability cores, less than $10 \%$. As $\mathrm{SiO}_{2} / \mathrm{P}(\mathrm{MBAAm}-\mathrm{co}-\mathrm{AM})$ suspension slug is injected, the fractional flows in high-permeability cores sharply decrease and in those low-permeability cores 
rapidly increase. Then, the fractional flows in low-permeability cores exceed those in high-permeability cores. At the end of $\mathrm{SiO}_{2} / \mathrm{P}(\mathrm{MBAAm}-\mathrm{co}-\mathrm{AM})$ suspension slug injection, the fractional flows increase to more than $60 \%$ in low-permeability cores, and decrease to less than $40 \%$ in high-permeability cores. The above changes of fractional flows in high- and low-permeability cores confirm that $\mathrm{SiO}_{2} / \mathrm{P}(\mathrm{MBAAm}-\mathrm{co}-\mathrm{AM})$ nanoparticles can block water channels in high-permeability cores to produce fluid diversion and enlarge the swept volume in low-permeability cores [55]. As the extended brine flooding starts, the fractional flows in high- and low-permeability cores both fluctuate with the migration of $\mathrm{SiO}_{2} / \mathrm{P}(\mathrm{MBAAm}-\mathrm{co}-\mathrm{AM})$ nanoparticles [56]. The fractional flows in low-permeability cores are always higher than those of high-permeability cores throughout the extended brine flood. This indicates that most of the $\mathrm{SiO}_{2} / \mathrm{P}(\mathrm{MBAAm}-\mathrm{co}-\mathrm{AM})$ nanoparticles flow into high-permeability cores and increase the flow resistance of the following brine.

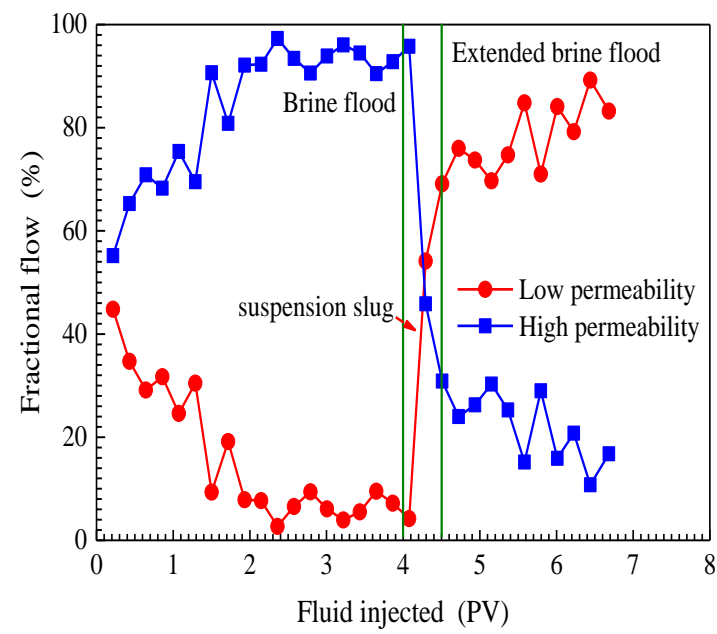

(a)

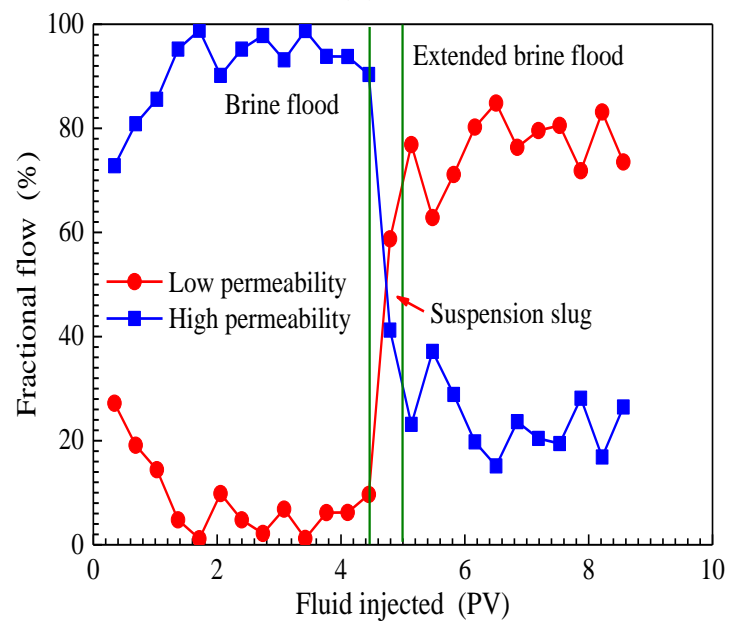

(c)

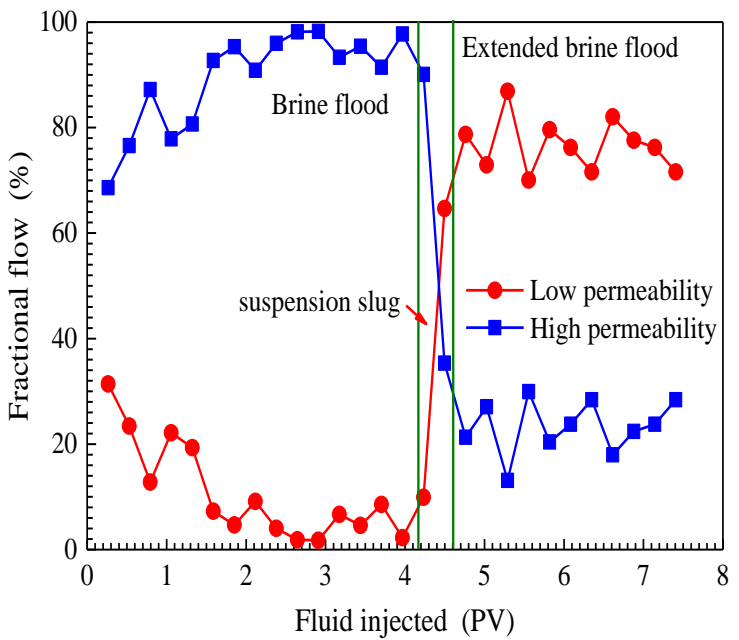

(b)

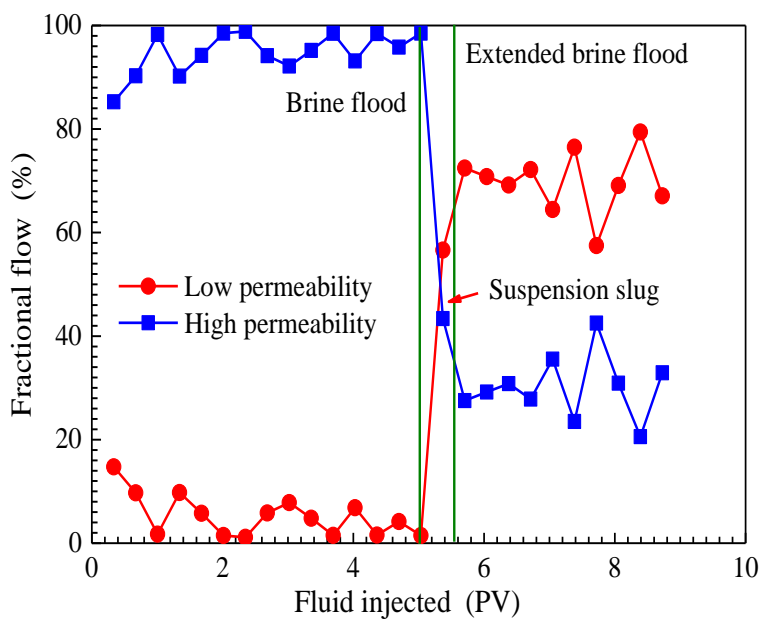

(d)

Figure 7. Fractional flow curves of four parallel cores flooding tests. Permeability ratio: (a) 1.40; (b) 4.36; (c) 8.28 ; (d) 15.49 .

In addition, it can be seen from Figure 7 that the permeability ratio of parallel cores has a significant effect on fractional flows. During the brine flooding, with an increase of permeability ratio from 1.40 to 15.49 , the initial difference of fractional flows in two cores increases from 10 to $60 \%$, and the breakthrough time of brine in high-permeability core decreases from 2.0 PV to 1.0 PV. Thus, it is evident that brine flooding is less effective as the permeability ratio of two cores becomes larger. When extended brine flood finishes, the difference of fractional flows in parallel cores decreases 
from 70 to $40 \%$ as the permeability ratio increases from 1.40 to 15.49 . The above results indicate that the greater the permeability ratio of two cores is, the more effective the profile control of the $\mathrm{SiO}_{2} / \mathrm{P}(\mathrm{MBAAm}-\mathrm{co}-\mathrm{AM})$ nanoparticles. When $\mathrm{SiO}_{2} / \mathrm{P}(\mathrm{MBAAm}-\mathrm{co}-\mathrm{AM})$ nanoparticles enter into cores, they can generate plugging at a pore throat, and some large nanoparticles are detained in pores. However, some nanoparticles can pass through pore throats by deformation under a driving pressure due to their ability to be elastic; then, the deformed nanoparticles can recover to their original shapes after entering into a larger pore. In addition, some nanoparticles break into smaller particles at the pore throat, which can pass through smaller pore throats. The plugging of these $\mathrm{SiO}_{2} / \mathrm{P}(\mathrm{MBAAm}-\mathrm{co}-\mathrm{AM})$ nanoparticles increases the flow resistance of blocked regions and diverts the fluid into low-resistance regions. Therefore, $\mathrm{SiO}_{2} / \mathrm{P}(\mathrm{MBAAm}-\mathrm{co}-\mathrm{AM})$ nanoparticles can effectively reduce the heterogeneity of reservoirs and improve the sweep efficiency.

\subsubsection{Effect of Permeability Ratio on Pressure Drop}

Pressure drop is defined as the pressure difference between the core inlet and outlet, which was determined by using pressure gauge [5]. The curves of pressure drop as a function of the pore volume of fluid injected under different permeability ratios are plotted in Figure 8. Each curve in Figure 8 reflects the similar variation of pressure drop with the pore volume of fluid injected. During the brine flooding, the pressure drop sharply rises in a very short time, and then falls. When brine breaks through into a high-permeability core, the pressure drop starts to remain almost constant. When the $\mathrm{SiO}_{2} / \mathrm{P}(\mathrm{MBAAm}-\mathrm{co}-\mathrm{AM})$ suspension slug injection starts, pressure drop raises rapidly, with tiny fluctuations. In the extended brine flood stage, the fluctuated pressure drop continues to rise until it reaches a maximum and then declines. These results indicate that the behaviors of $\mathrm{SiO}_{2} / \mathrm{P}(\mathrm{MBAAm}-\mathrm{co}-\mathrm{AM})$ nanoparticles at pore throats can result in a fluctuation of pressure drop. According to Darcy's law, the fluctuated pressure drop can lead to a fluctuation of fractional flow, which is consistent with the experimental results of fractional flow. In addition, pressure drop in different parallel cores increases with increasing permeability ratios. During the extended brine flood, the maximum pressure drop rises from $0.26 \mathrm{MPa}$ to $0.61 \mathrm{MPa}$ when the permeability ratio increases from 1.40 to 15.49 . As the permeability ratio of the parallel cores increases, the blockage of $\mathrm{SiO}_{2} / \mathrm{P}(\mathrm{MBAAm}-\mathrm{co}-\mathrm{AM})$ nanoparticles in the core becomes stronger so that a greater pressure drop is obtained. The fluid can enter into smaller pores, and its swept volume is enlarged. Hence, it can be concluded that $\mathrm{SiO}_{2} / \mathrm{P}(\mathrm{MBAAm}-\mathrm{co}-\mathrm{AM})$ nanoparticles have a better profile control effect for more heterogeneous media.

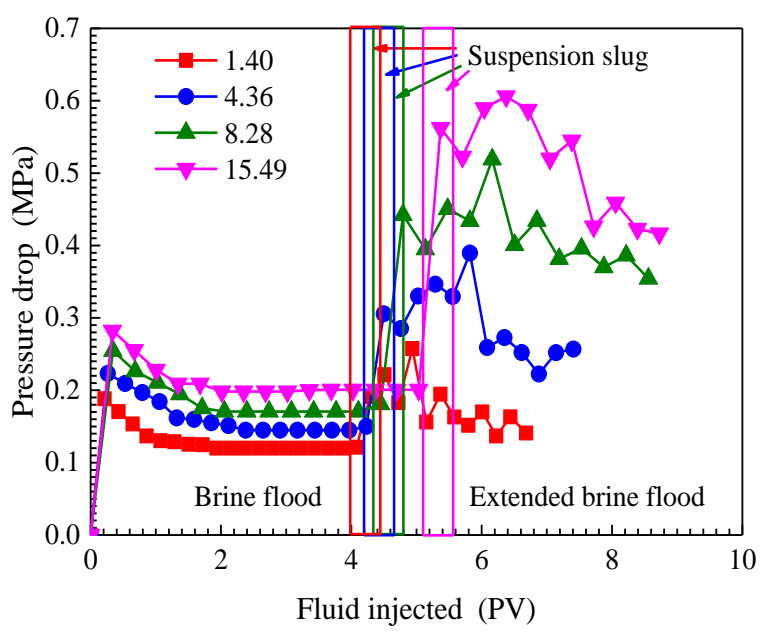

Figure 8. Curves of pressure drop as a function of the pore volume of fluid injected under different permeability ratios. 


\subsubsection{Effect of Permeability Ratio on EOR}

The cumulative oil recoveries of four parallel core flooding tests are plotted as a function of the pore volume of fluid injected in Figure 9. Each of the diagrams in Figure 9 has two curves representing a high-permeability core and low-permeability core. The cumulative oil recovery includes all three flooding stages-initial brine flood, $\mathrm{SiO}_{2} / \mathrm{P}(\mathrm{MBAAm}-\mathrm{co}-\mathrm{AM})$ suspension slug injection, and extended brine flood. The results of four tests show that during the initial brine flooding, oil recoveries of low-permeability cores are less than those of high-permeability cores. Moreover, this difference increases with an increasing permeability ratio of parallel cores. When permeability ratios are 1.40 , $4.36,8.28$, and 15.49 , brine flood recovers $52.37 \%, 53.84 \%, 55.49 \%$, and $56.69 \%$ of the initial oil in place (IOIP) of high-permeability cores, respectively, which are all higher than the cumulative oil recoveries of low-permeability cores in the same parallel cores: $46.70 \%, 29.79 \%$, $22.99 \%$, and $17.61 \%$ IOIP. The test results illustrate that a high permeability ratio can result in high residual oil saturation in low-permeability cores.

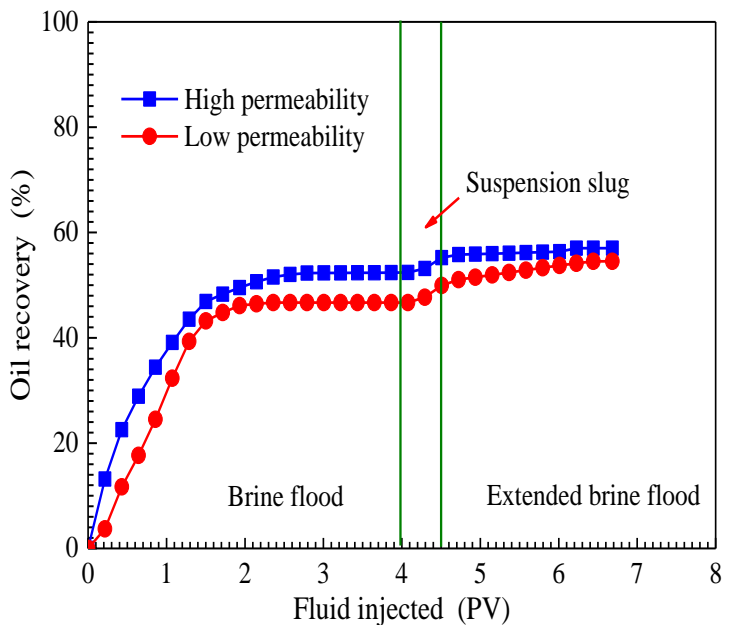

(a)

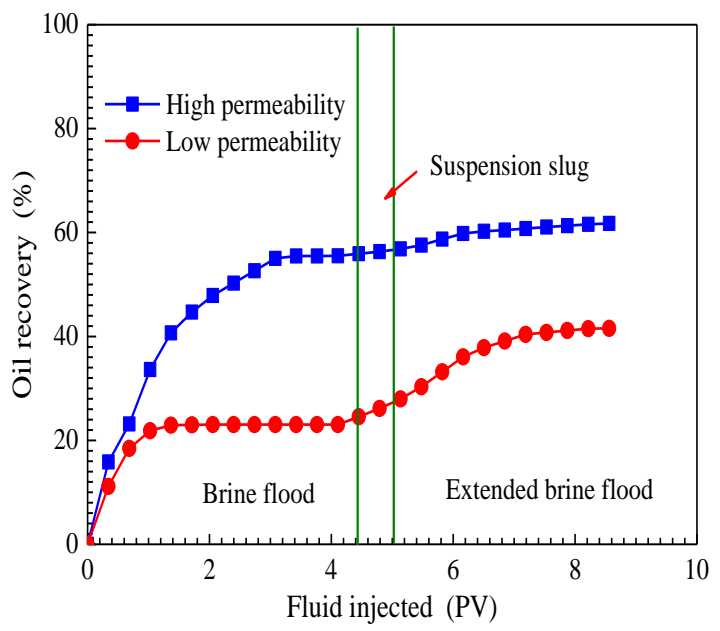

(c)

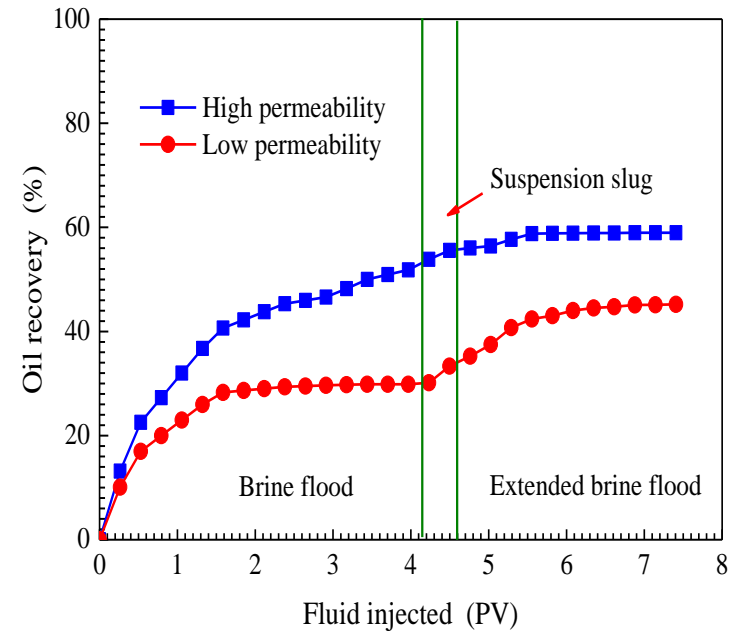

(b)

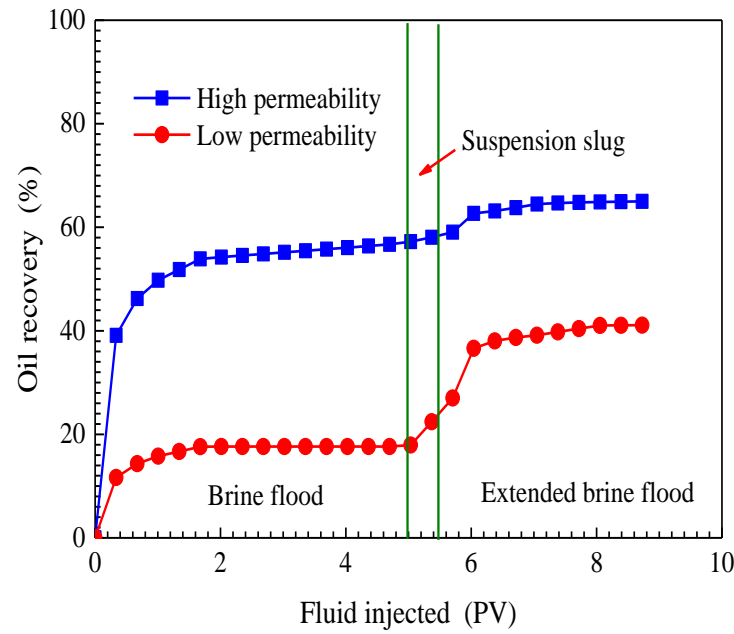

(d)

Figure 9. Cumulative oil recoveries of four parallel cores flooding tests. Permeability ratio: (a) 1.40; (b) 4.36 ; (c) 8.28 ; (d) 15.49 .

For the purpose of improving oil recovery in heterogeneous reservoirs, a slug of $\mathrm{SiO}_{2} /$ $\mathrm{P}(\mathrm{MBAAm}-\mathrm{co}-\mathrm{AM})$ suspension was injected into parallel cores. As seen in Figure 9, in the slug injection stage, both oil recovery curves rise, and the curve of the high-permeability core rises much slower than that of the low-permeability core. This indicates that most $\mathrm{SiO}_{2} / \mathrm{P}(\mathrm{MBAAm}-\mathrm{co}-\mathrm{AM})$ 
composite nanoparticles enter into high-permeability cores to perform effective plugging at throats. Therefore, the flow resistance in high-permeability cores is increased, and the major flow passage in parallel cores can be diverted from the high-permeability core to the low-permeability core by the injected $\mathrm{SiO}_{2} / \mathrm{P}(\mathrm{MBAAm}-\mathrm{co}-\mathrm{AM})$ suspension. Because most of the injected $\mathrm{SiO}_{2} / \mathrm{P}(\mathrm{MBAAm}-\mathrm{co}-\mathrm{AM})$ composite nanoparticles are detained in high-permeability cores, the effect of enlarging the sweep volume continues during the extended brine flood. It can be seen from the oil recovery curves of the extended brine flood that the cumulative oil recoveries in low-permeability cores are $54.39 \%, 46.06 \%$, $41.57 \%$, and $41.22 \%$ IOIP for tests $1,2,3$, and 4, respectively, which are still less than those of the high-permeability cores in the same parallel cores: $56.98 \%, 58.82 \%, 61.74 \%$, and $65.15 \%$ IOIP for tests $1,2,3$, and 4 . However, compared with the test results of brine flood, the difference between the oil recovery of a high-permeability core and that of a low-permeability core in the same parallel cores reduces after the extended brine flood. Meanwhile, it can be noticed from Table 1 that the incremental oil recoveries in low-permeability cores, by $\mathrm{SiO}_{2} / \mathrm{P}(\mathrm{MBAAm}-\mathrm{co}-\mathrm{AM})$ suspension injection and the following extended brine flood, are much higher than those in high-permeability cores. The ratios of incremental oil recoveries (low permeability/high permeability) are 7.69/4.61, 16.27/4.98, 18.58/6.25, and $23.61 / 8.46$ for tests $1,2,3$, and 4 , respectively. Thus, it is obvious that a high permeability ratio can result in a high incremental oil recovery in a low-permeability core. The above results illustrate that the injection of $\mathrm{SiO}_{2} / \mathrm{P}(\mathrm{MBAAm}-\mathrm{co}-\mathrm{AM})$ suspension can effectively improve the sweep efficiency and recover more residual oil in a heterogeneous, low-permeability reservoir. Moreover, the effect of $\mathrm{SiO}_{2} / \mathrm{P}(\mathrm{MBAAm}-\mathrm{co}-\mathrm{AM})$ suspension on enlarging the sweep efficiency becomes more noticeable in a more heterogeneous, low-permeability reservoir.

In order to investigate the relationship between pressure drop and EOR in four parallel core flooding tests, the incremental oil recoveries in high- and low-permeability cores were plotted as a function of the maximal pressure drop at each permeability ratio, as shown in Figure 10. The largest maximum pressure drop occurs at a higher permeability ratio. It can be observed that, with an increase of permeability ratio and maximal pressure drop, an improvement in EOR is denoted by an increase from 4.61 to $8.46 \%$ in high-permeability cores (Figure 10a) and from 7.69 to $23.61 \%$ in low-permeability cores (Figure 10b). This indicates that the $\mathrm{SiO}_{2} / \mathrm{P}(\mathrm{MBAAm}-\mathrm{co}-\mathrm{AM})$ suspension is appropriate to be applied to improve oil recovery in heterogeneous, low-permeability reservoirs.

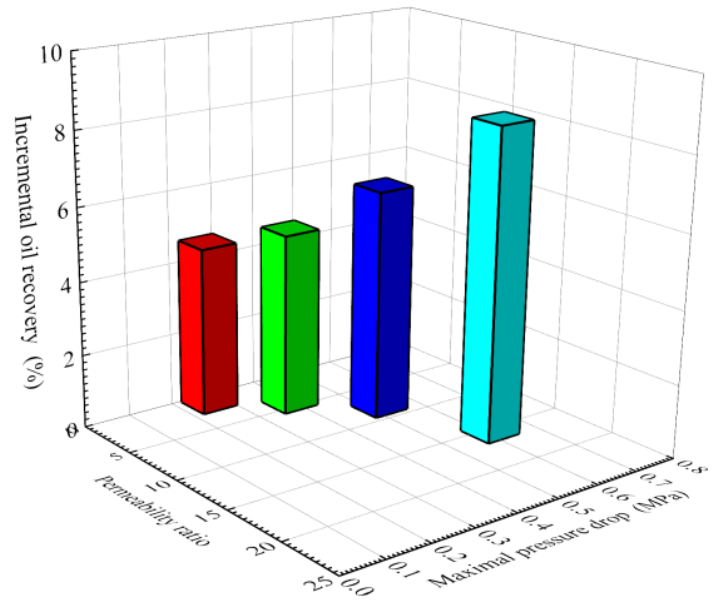

(a)

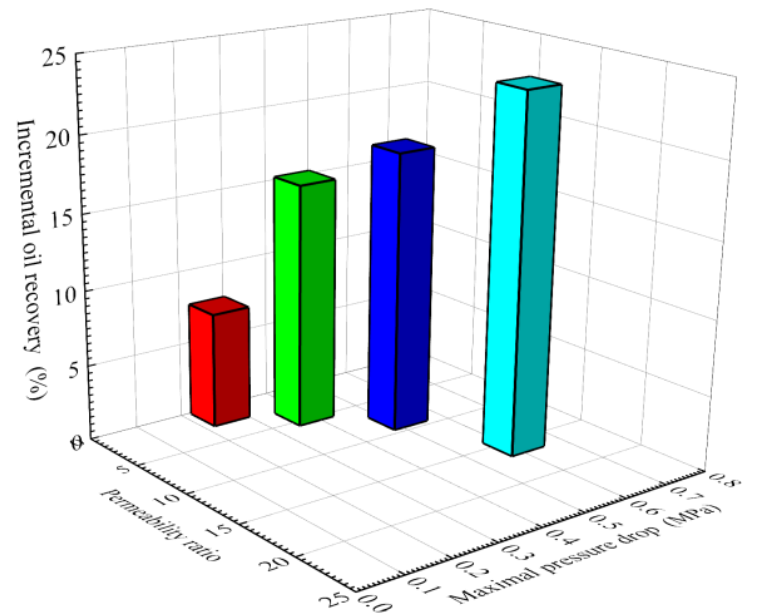

(b)

Figure 10. Effect of permeability ratio and maximal pressure drop on incremental oil recovery: (a) high-permeability cores; (b) low-permeability cores. 


\section{Conclusions}

In summary, $\mathrm{SiO}_{2} / \mathrm{P}(\mathrm{MBAAm}-\mathrm{co}-\mathrm{AM})$ composite nanoparticles have been successfully synthesized by a distillation-precipitation polymerization method. Their morphology and microstructure were ascertained by TEM, FT-IR, and TGA. The swelling performances of $\mathrm{SiO}_{2} / \mathrm{P}(\mathrm{MBAAm}-\mathrm{co}-\mathrm{AM})$ nanoparticles and the rheological behaviors and efficiency of $\mathrm{SiO}_{2} / \mathrm{P}(\mathrm{MBAAm}-\mathrm{co}-\mathrm{AM})$ suspension in EOR were investigated. The main results can be summarized as follows:

(1) $\mathrm{SiO}_{2} / \mathrm{P}(\mathrm{MBAAm}-\mathrm{co}-\mathrm{AM})$ nanoparticles exhibit a favorable swelling property in an aqueous solution and their particle sizes increase from 631 to $1258 \mathrm{~nm}$ as the swelling times increase from 24 to $120 \mathrm{~h}$.

(2) The apparent viscosity of $\mathrm{SiO}_{2} / \mathrm{P}(\mathrm{MBAAm}-\mathrm{co}-\mathrm{AM})$ suspension increases with an increase of mass concentration and swelling time, whereas it decreases as salinity and temperature increase. The $\mathrm{SiO}_{2} / \mathrm{P}(\mathrm{MBAAm}-\mathrm{co}-\mathrm{AM})$ suspension behaves like a non-Newtonian fluid at lower shear rates, whereas it represents a Newtonian fluid behavior at shear rates greater than $300 \mathrm{~s}^{-1}$.

(3) $\mathrm{SiO}_{2} / \mathrm{P}(\mathrm{MBAAm}-\mathrm{co}-\mathrm{AM})$ nanoparticles can effectively reduce the heterogeneity of reservoirs and improve the sweep efficiency. A high permeability ratio can result in a high incremental oil recovery in parallel cores. When the permeability ratio increases from 1.40 to 15.49 , the incremental oil recoveries rise from 4.61 to $8.46 \%$ and from 7.69 to $23.61 \%$ in high- and low-permeability cores, respectively.

Despite the fact that the $\mathrm{SiO}_{2} / \mathrm{P}(\mathrm{MBAAm}-\mathrm{co}-\mathrm{AM})$ suspension is appropriate to be applied to improve oil recovery in heterogeneous, low-permeability reservoirs, there are two major limitations in this study that could be addressed in future research. First, this study focused on the effect of permeability ratio on EOR, yet it did not discuss the influence of nanoparticle properties on EOR. Second, this study lacked core samples from representative blocks of low-permeability reservoirs.

Author Contributions: Y.L. designed the experiments; Y.L., Z.L., and X.H. performed the experiments; Y.L. and R.W. analyzed the data; B.Z., L.C., and F.S. assisted with the characterizations; Y.L. wrote, revised, and edited the paper.

Funding: This work was financially supported by the Natural Science Foundation of Zhejiang Province (Project No.: LY19A020004, LY19E010005), the National Natural Science Foundation of China (Project No.: 11602221, 11472246), the General Research Projects of Zhejiang Provincial Department of Education (Project No.: Y201840296), and the Cultivation Project of Zhejiang Ocean University (Project No.: 2015A13).

Conflicts of Interest: The authors declare no conflict of interest.

\section{References}

1. Zeng, L.; Liu, H. Influence of fractures on the development of low-permeability sandstone reservoirs: A case study from the Taizhao district, Daqing Oilfield, China. J. Petrol. Sci. Eng. 2010, 72, 120-127. [CrossRef]

2. $\mathrm{Pu}, \mathrm{C}$.; Jing, C.; He, Y.; Gu, X.; Zhang, Z.; Wei, J. Multistage interwell chemical tracing for step-by-step profile control of water channeling and flooding of fractured ultra-low permeability reservoirs. Petrol. Explor. Dev. 2016, 43, 679-688. [CrossRef]

3. Wang, X.; Dang, H.; Gao, T. Method of moderate water injection and its application in ultra-low permeability oil reservoirs of Yanchang Oilfield, NW China. Petrol. Explor. Dev. 2018, 45, 1094-1102. [CrossRef]

4. Zhao, X.; Zhang, J.; He, Q.; Tan, X. Experimental study and application of anti-salt polymer aqueous solutions prepared by produced water for low-permeability reservoirs. J. Petrol. Sci. Eng. 2019, 175, 480-488. [CrossRef]

5. Sang, Q.; Li, S.; Yu, L.; Li, Z.; Dong, M. Enhanced oil recovery by branched-preformed particle gel injection in parallel-sandpack models. Fuel 2014, 136, 295-306. [CrossRef]

6. Dejam, M. Advective-diffusive-reactive solute transport due to non-Newtonian fluid flows in a fracture surrounded by a tight porous medium. Int. J. Heat. Mass. Tran. 2019, 128, 1307-1321. [CrossRef]

7. Zhang, L.; Kou, Z.; Wang, H.; Zhao, Y.; Dejam, M.; Guo, J.; Du, J. Performance analysis for a model of a multi-wing hydraulically fractured vertical well in a coalbed methane gas reservoir. J. Petrol. Sci. Eng. 2018, 166, 104-120. [CrossRef] 
8. Li, T.; Song, H.; Wang, J.; Wang, Y.; Killough, J. An analytical method for modeling and analysis gas-water relative permeability in nanoscale pores with interfacial effects. Int. J. Coal. Geol. 2016, 159, 71-81. [CrossRef]

9. Yu, L.; Dong, M.; Ding, B.; Yuan, Y. Experimental study on the effect of interfacial tension on the conformance control of oil-in-water emulsions in heterogeneous oil sands reservoirs. Chem. Eng. Sci. 2018, 189, 165-178. [CrossRef]

10. Dejam, M.; Hassanzadeh, H.; Chen, Z. Pre-Darcy flow in porous media. Water. Resour. Res. 2017, 53, 8187-8210. [CrossRef]

11. Song, H.; Yu, M.; Zhu, W.; Wu, P.; Lou, Y.; Wang, Y.; Killough, J. Numerical investigation of gas flow rate in shale gas reservoirs with nanoporous media. Int. J. Heat. Mass. Tran. 2015, 80, 626-635. [CrossRef]

12. Gu, M.; Chen, X.; Wu, C.; He, X.; Chu, H.; Liu, F. Effects of particle size distribution and oxygenconcentration on the propagation behavior of pulverized coal flames in $\mathrm{O}_{2} / \mathrm{CO}_{2}$ atmospheres. Energy Fuel 2017, 31, 5571-5580. [CrossRef]

13. Soleimani, M. Well performance optimization for gas lift operation in a heterogeneous reservoir by fine zonation and different well type integration. J. Nat. Gas Sci. Eng. 2017, 40, 277-287. [CrossRef]

14. He, L.; Mei, H.; Hu, X.; Dejam, M.; Kou, Z.; Zhang, M. Advanced flowing material balance to determine original gas-in-place of shale gas considering adsorption hysteresis. SPE Reserv. Eval. Eng. 2019. [CrossRef]

15. Song, H.; Cao, Y.; Yu, M.; Wang, Y.; Killough, J.; Leung, J. Impact of permeability heterogeneity on production characteristics in water-bearing tight gas reservoirs with threshold pressure gradient. J. Nat. Gas Sci. Eng. 2015, 22, 172-181. [CrossRef]

16. Xu, P.; Qiu, S.; Cai, J.; Li, C.; Liu, H. A novel analytical solution for gas diffusion in multi-scale fuel cell porous media. J. Power Sources 2017, 362, 73-79. [CrossRef]

17. Brattekås, B.; Seright, R.S. Implications for improved polymer gel conformance control during low-salinity chase-floods in fractured carbonates. J. Petrol. Sci. Eng. 2018, 163, 661-670. [CrossRef]

18. Wang, J.; Liu, H. A novel model and sensitivity analysis for viscoelastic polymer flooding in offshore oilfield. J. Ind. Eng. Chem. 2014, 20, 656-667. [CrossRef]

19. Amirian, E.; Dejam, M.; Chen, Z. Performance forecasting for polymer flooding in heavy oil reservoirs. Fuel 2018, 216, 83-100. [CrossRef]

20. Saboorian-Jooybari, H.; Dejam, M.; Chen, Z. Heavy oil polymer flooding from laboratory core floods to pilot tests and field applications: Half-century studies. J. Petrol. Sci. Eng. 2016, 142, 85-100. [CrossRef]

21. Bahrami, P.; Kazemi, P.; Mahdavi, S.; Ghobadi, H. A novel approach for modeling and optimization of surfactant/polymer flooding based on Genetic Programming evolutionary algorithm. Fuel 2016, 179, $289-298$. [CrossRef]

22. Fu, L.; Zhang, G.; Ge, J.; Liao, K.; Pei, H.; Jiang, P.; Li, X. Study on organic alkali-surfactant-polymer flooding for enhanced ordinary heavy oil recovery. Colloids Surf. A 2016, 508, 230-239. [CrossRef]

23. Mashayekhizadeh, V.; Kord, S.; Dejam, M. EOR potential within Iran. Spec. Top. Rev. Porous Media 2014, 5, 325-354. [CrossRef]

24. Zhao, F.; Lv, C.; Hou, J.; Wang, Z. Formation adaptability of combining modified starch gel and nitrogen foam in profile modification and oil displacement. J. Energy Inst. 2016, 89, 536-543. [CrossRef]

25. Karambeigi, M.S.; Abbassi, R.; Roayaei, E.; Emadi, M.A. Emulsion flooding for enhanced oil recovery: Interactive optimization of phase behavior, microvisual and core-flood experiments. J. Ind. Eng. Chem. 2015, 29, 382-391. [CrossRef]

26. Olayiwola, S.O.; Dejam, M. A comprehensive review on interaction of nanoparticles with low salinity water and surfactant for enhanced oil recovery in sandstone and carbonate reservoirs. Fuel 2019, 241, 1045-1057. [CrossRef]

27. Cheraghian, G. Evaluation of clay and fumed silica nanoparticles on adsorption of surfactant polymer during enhanced oil recovery. J. Jpn. Petrol. Inst. 2017, 60, 85-94. [CrossRef]

28. Almahfood, M.; Bai, B. The synergistic effects of nanoparticle-surfactant nanofluids in EOR applications. J. Petrol. Sci. Eng. 2018, 171, 198-210. [CrossRef]

29. Gbadamosi, A.O.; Junin, R.; Manan, M.A.; Yekeen, N.; Agi, A.; Oseh, J.O. Recent advances and prospects in polymeric nanofluids application for enhanced oil recovery. J. Ind. Eng. Chem. 2018, 66, 1-19. [CrossRef]

30. Wei, B.; Li, Q.; Ning, J.; Wang, Y.; Sun, L.; Pu, W. Macro- and micro-scale observations of a surface-functionalized nanocellulose based aqueous nanofluids in chemical enhanced oil recovery (C-EOR). Fuel 2019, 236, 1321-1333. [CrossRef] 
31. Soleimani, H.; Baig, M.K.; Yahya, N.; Khodapanah, L.; Sabet, M.; Demiral, B.M.R.; Burda, M. Impact of carbon nanotubes based nanofluid on oil recovery efficiency using core flooding. Results Phys. 2018, 9, 39-48. [CrossRef]

32. Olayiwola, S.O.; Dejam, M. Mathematical modelling of surface tension of nanoparticles in electrolyte solutions. Chem. Eng. Sci. 2019, 197, 345-356. [CrossRef]

33. Cheraghian, G. Synthesis and properties of polyacrylamide by nanoparticles, effect nanoclay on stability polyacrylamide solution. Micro Nano Lett. 2016, 12, 40-44. [CrossRef]

34. Sharma, T.; Sangwai, J.S. Silica nanofluids in polyacrylamide with and without surfactant: Viscosity, surface tension, and interfacial tension with liquid paraffin. J. Petrol. Sci. Eng. 2017, 152, 575-585. [CrossRef]

35. Cheraghian, G. Thermal resistance and application of nanoclay on polymer flooding in heavy oil recovery. Petrol. Explor. Dev. 2015, 33, 1580-1586. [CrossRef]

36. Chu, H.; Han, W.; Cao, W.; Gu, M.; Xu, G. Effect of methane addition to ethylene on the morphology and size distribution of soot in a laminar co-flow diffusion flame. Energy 2019, 166, 392-400. [CrossRef]

37. Cheraghian, G. Application of nano-fumed silica in heavy oil recovery. Petrol. Explor. Dev. 2016, 34, 12-18. [CrossRef]

38. Xu, P.; Li, C.; Qiu, S.; Sasmito, A.P. A fractal network model for fractured porous media. Fractals 2016, 24, 1650018. [CrossRef]

39. Cheraghian, G. Effect of nano titanium dioxide on heavy oil recovery during polymer flooding. Petrol. Explor. Dev. 2016, 34, 633-641. [CrossRef]

40. Lai, N.; Guo, X.; Zhou, N.; Xu, Q. Shear Resistance Properties of Modified Nano-SiO $2 / A A / A M$ Copolymer Oil Displacement Agent. Energies 2016, 9, 1037. [CrossRef]

41. Hu, Z.; Haruna, M.; Gao, H.; Nourafkan, E.; Wen, D. Rheological properties of partially hydrolyzed polyacrylamide seeded by nanoparticles. Ind. Eng. Chem. Res. 2017, 56, 3456-3463. [CrossRef]

42. Ju, B.; Fan, T. Experimental study and mathematical model of nanoparticle transport in porous media. Powder Technol. 2009, 192, 195-202. [CrossRef]

43. Liu, R.; Pu, W.; Sheng, J.J.; Du, D. Star-like hydrophobically associative polyacrylamide for enhanced oil recovery: Comprehensive properties in harsh reservoir conditions. J. Taiwan. Inst. Chem. E 2017, 80, 639-649. [CrossRef]

44. Caparrós, C.; Benelmekki, M.; Martins, P.M.; Xuriguera, E.; Silva, C.J.R.; Martinez, L.M. Hydrothermal assisted synthesis of iron oxide-based magnetic silica spheres and their performance in magnetophoretic water purification. Mater. Chem. Phys. 2012, 135, 510-517. [CrossRef]

45. Effati, E.; Pourabbas, B. Synthesis of core-shell poly (N-isopropylacrylamide) grafted silica nanoparticles by distillation precipitation polymerization. Powder Technol. 2013, 246, 472-477. [CrossRef]

46. Mauriello, F.; Garrone, E.; Musolino, M.G.; Pietropaolo, R.; Onida, B. Conversion of cis-2-butene-1,4-diol to hydrofurans on $\mathrm{Pd} / \mathrm{SiO}_{2}$ and $\mathrm{Pt} / \mathrm{SiO}_{2}$ catalysts under mild conditions: A FT-IR study. J. Mol. Catal. A Chem. 2010, 328, 27-34. [CrossRef]

47. Kiviaho, J.; Niemelä, M.K.; Reinikainen, M.; Pakkanen, T.A. TPR and FT-IR studies on carbonyl cluster derived $\mathrm{Co}-\mathrm{Ru} / \mathrm{SiO}_{2}$ catalysts. Appl. Catal. A Gen. 1997, 149, 353-372. [CrossRef]

48. Nagai, N.; Hashimoto, H. FT-IR-ATR study of depth profile of $\mathrm{SiO}_{2}$ ultra-thin films. Appl. Surf. Sci. 2001, 172, 307-311. [CrossRef]

49. Rezaei, A.; Khangah, M.A.; Mohebbi, A.; Tatar, A.; Mohammadi, A.H. Using surface modified clay nanoparticles to improve rheological behavior of Hydrolized Polyacrylamid (HPAM) solution for enhanced oil recovery with polymer flooding. J. Mol. Liq. 2016, 222, 1148-1156. [CrossRef]

50. El-hoshoudy, A.N. Synthesis of acryloylated starch-g-poly acrylates crosslinked polymer functionalized by emulsified vinyltrimethylsilane derivative as a novel EOR agent for severe polymer flooding strategy. Int. J. Biol. Macromol. 2019, 123, 124-132. [CrossRef]

51. Frost, R.L.; Kloprogge, J.; Russell, S.C.; Szetu, J.L. Dehydroxylation and structure of alumina gels prepared from trisecbutoxyaluminium. Thermochim. Acta 1999, 329, 47-56. [CrossRef]

52. Frost, R.L.; Erickson, K.L. Decomposition of the synthetic hydrotalcites mountkeithite and honessite-A high resolution thermogravimetric analysis and infrared emission spectroscopic study. Thermochim. Acta 2004, 421, 51-58. [CrossRef]

53. Soltani, O.; Akbari, M. Effects of temperature and particles concentration on the dynamic viscosity of MgO-MWCNT/ethylene glycol hybrid nanofluid: Experimental study. Phys. E 2016, 84, 564-570. [CrossRef] 
54. Atashrouz, S.; Mozaffarian, M.; Pazuki, G. Viscosity and rheological properties of ethylene glycol+ water+ $\mathrm{Fe}_{3} \mathrm{O}_{4}$ nanofluids at various temperatures: Experimental and thermodynamics modeling. Korean J. Chem. Eng. 2016, 33, 2522-2529. [CrossRef]

55. Yue, M.; Zhu, W.; Han, H.; Song, H.; Long, Y.; Lou, Y. Experimental research on remaining oil distribution and recovery performances after nano-micron polymer particles injection by direct visualization. Fuel 2018, 212, 506-514. [CrossRef]

56. Esfe, M.H.; Raki, H.R.; Emami, M.R.S.; Afrand, M. Viscosity and rheological properties of antifreeze based nanofluid containing hybrid nano-powders of $\mathrm{MWCNTs}$ and $\mathrm{TiO}_{2}$ under different temperature conditions. Powder Technol. 2019, 342, 808-816. [CrossRef]

(C) 2019 by the authors. Licensee MDPI, Basel, Switzerland. This article is an open access article distributed under the terms and conditions of the Creative Commons Attribution (CC BY) license (http://creativecommons.org/licenses/by/4.0/). 